\title{
$\overline{\underline{ }}$ \\ Journal of Home \\ Economics
}

\author{
مجلة الإقتصاد المنزلى مجلى

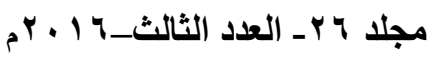

\section{http://homeEcon.menofia.edu.eg}

ISSN 1110-2578
" منظور وظيفي وجمالى لملابس مرضي (خشونة المفاصل - الروماتيود) من

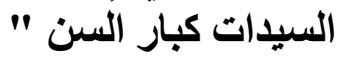

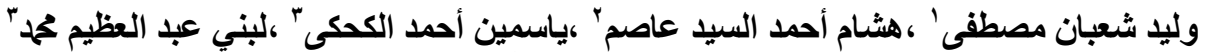

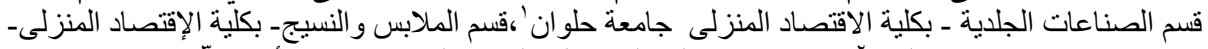

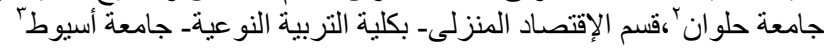

يمر الإنسان بمراحل ثلاث مرحلة الضعف الأولى ( الطفولة ) ثم مرحلة القوة

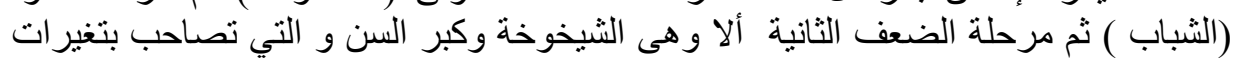

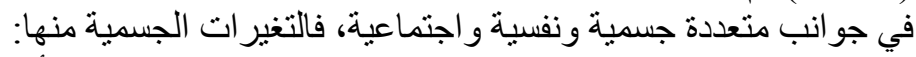

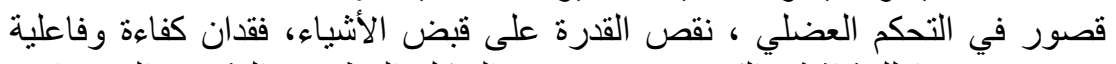

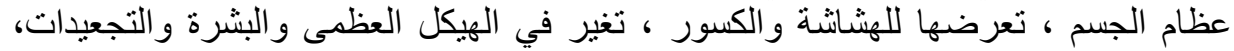

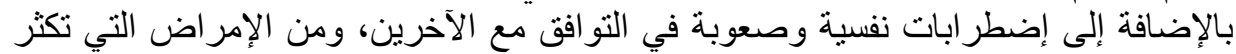

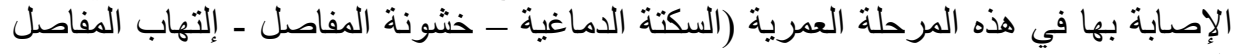

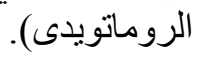

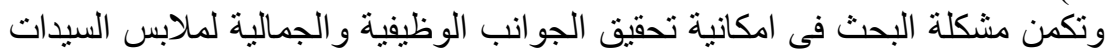

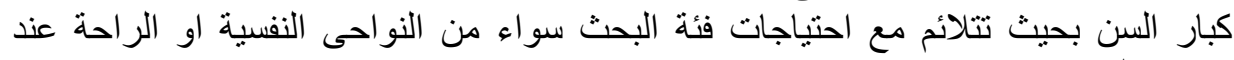

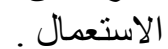

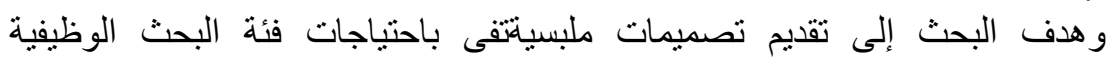

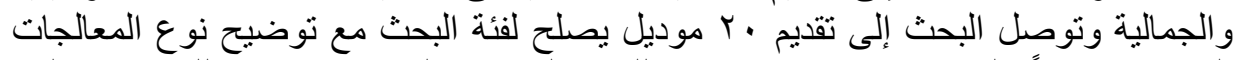

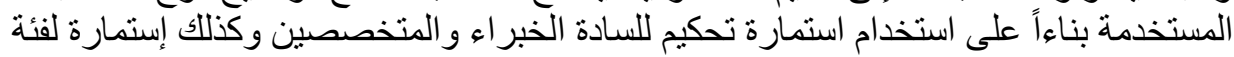

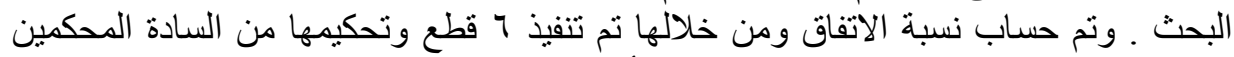

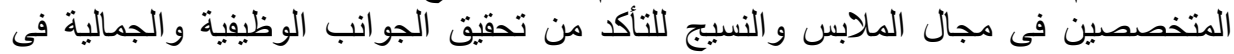

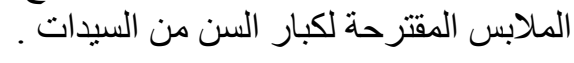

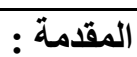

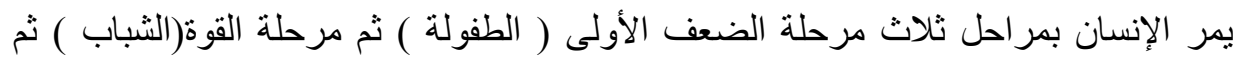

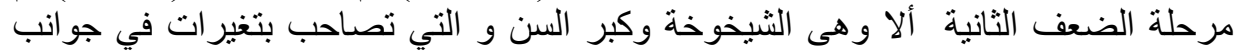

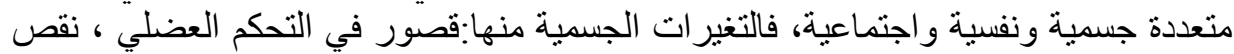

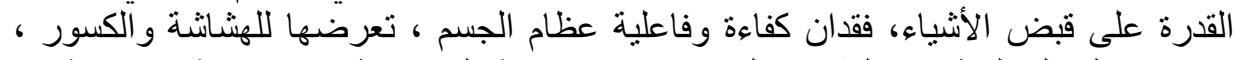

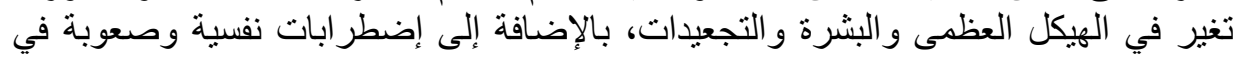


التو افق مع الآخرين، ومن الإمراض التي تكثر الإصـابة بها في هذه المرحلة العمرية (السكتة

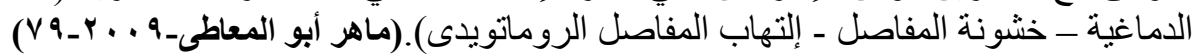

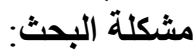
ويمكن صياغة مشكلة البحثث في الإجابة عن التساؤلات الآتية:

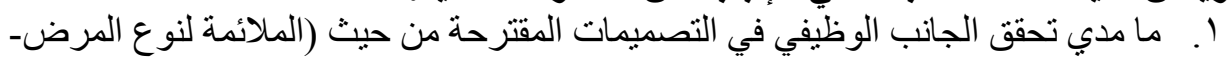

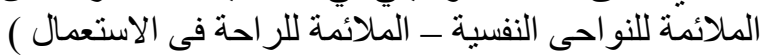

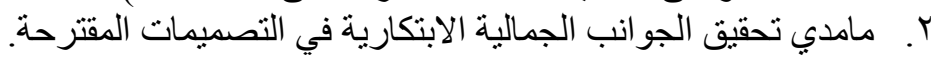

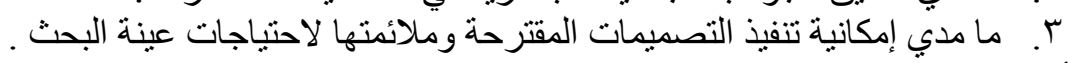

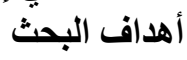
ا ـ التعرف على الصعوبات الملبسية التى تواجة مرضي (خشونة المفاصل ـ الروماتيود)من

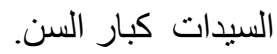
r. التعرف على المنطلبات الملبسية (الوظيفية و الجمالية) الخاصة بالفئات الخاصة من السيدات

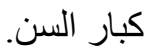
r. تقديم مقترحات تصميمية لمجموعة من الملابس الخارجية الخاصة تنتاسب الحالات

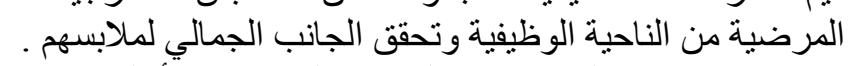

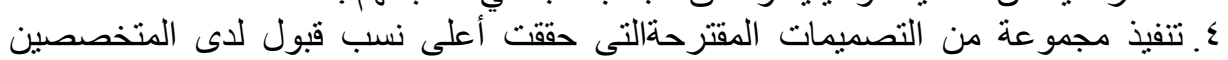
و المستهلكين.

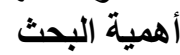

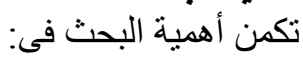

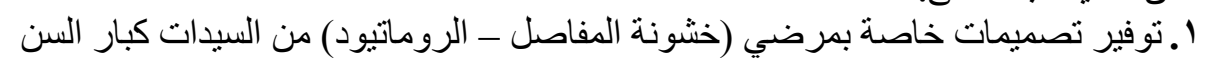

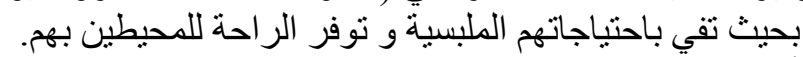

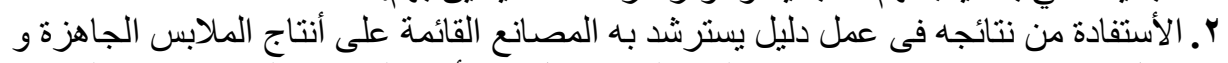

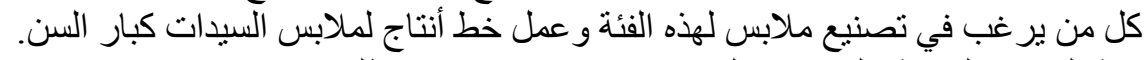

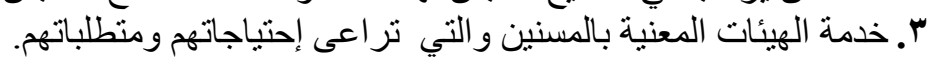

1- التصميمات المقترحة تحقق الجانب الوظيفى للسيدات كبار السن وتناسب الاحتياجات

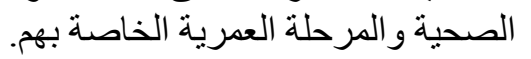
r- التصميمات المقترحة تؤثر إيجابيا على الحالة النفسية للسيدات كبار السن.

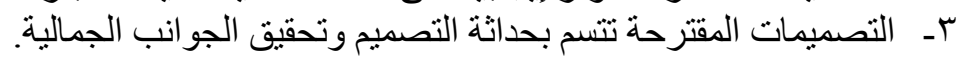

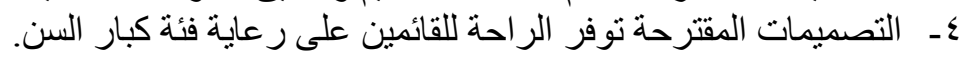

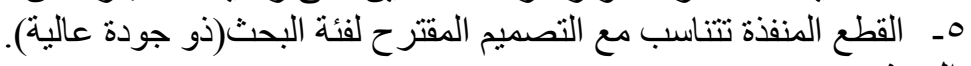

يتحدد النطاق الجغر افي للار اسة في جنوب الصعيد وبالتحديد في مدينة أسيوط فئ:

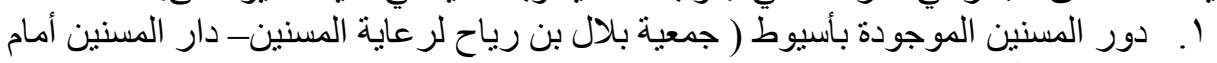

$$
\begin{aligned}
& \text { مستشفى المبرة ). } \\
& \text { r. مستشفى جامعة أسيوط قسم العلاج لطبيعى و الروماتويد. }
\end{aligned}
$$


مجلة الإقتصاد المنزلى- مجلد 7 ـ العدد الثالث_r 1 • r م

ع. ع. مستشفى المبرة بأسيوط.

ع. العاملين بجامعة أسيوط.

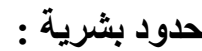

أتتمثل الحدود البشرية في عينة حجمها( • ه شخصاً) من كبار السن السيدات الذين تتر اوح

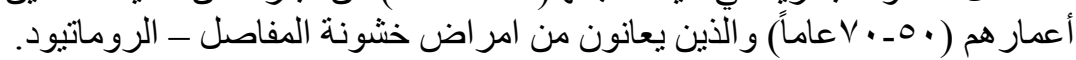

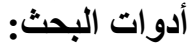

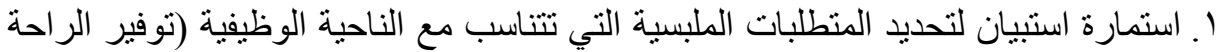

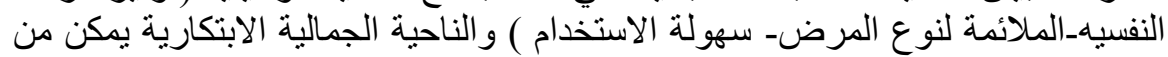

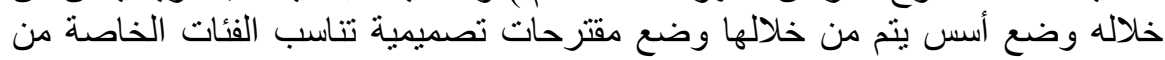

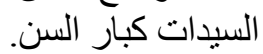

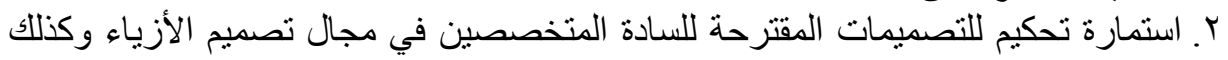
عينه البحث و القائمين على لتهيم رعايتهم. ب. استمارة تقييم للقطع المنفذة للمتخصصين على عائهن في مجال الملابس و النسيج. منهج البحث: المنه: المنهج الوصفي التجريبى: وتضمن الأتى :

أ. حصر وتحليلّ وتجميع الدراسات السابقة ووضع الإنيات الإطار النظري الخاص بالبحث.

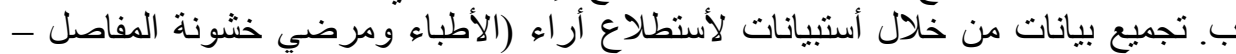

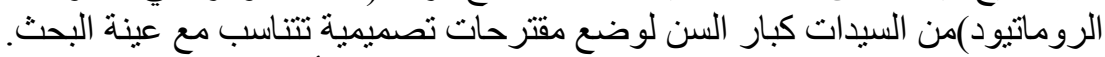

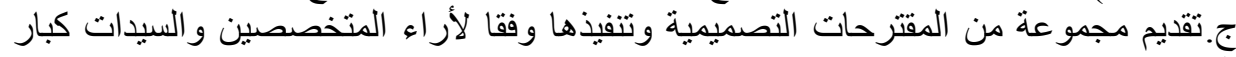
السن.

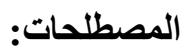

ـ تعريف كبار السن:هم الأشخاص ذكور اً أو إنانا الذين تجاوزوا مر احل النمو و التطور و البناء

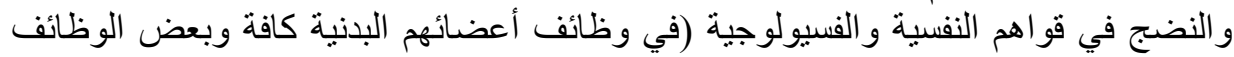

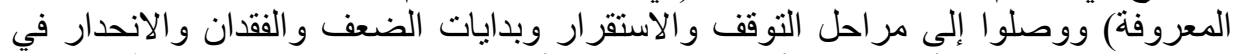

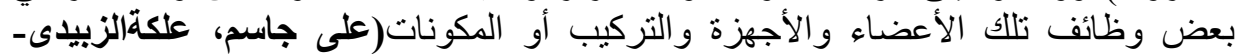

(ro_r. a 9

ـ مرض الروماتيد: (التهاب المفاصل )هو من إمر اض المقاعد الذاتية التي تؤُثر على المفاصل

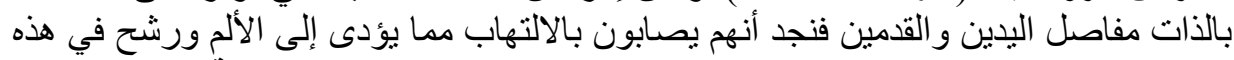

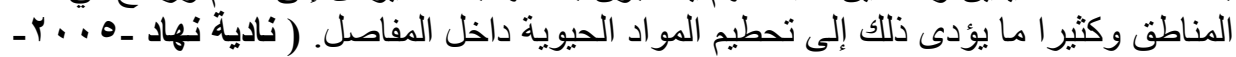

(1).

ـ مفهوم الخشونة: حيث يتحول فيها الغضروف الناعم الأملس إلي سطح متآكل خشن ويرق

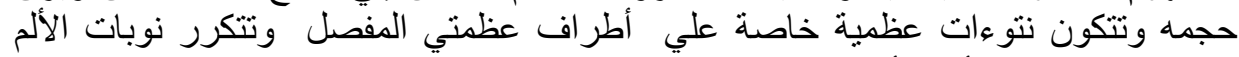

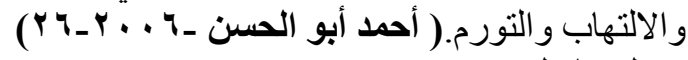

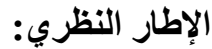

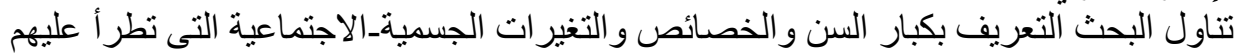

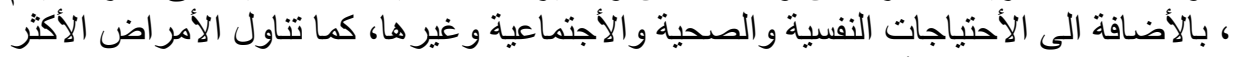

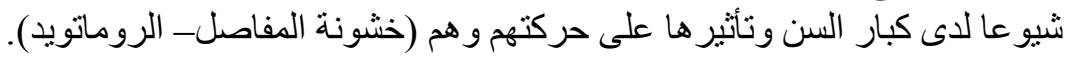




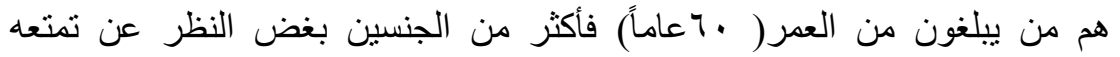

تعريف المسنين:

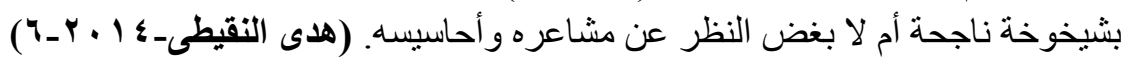
خصائص مرحلة الكبر والتغيرات التي تطرأ لألها:

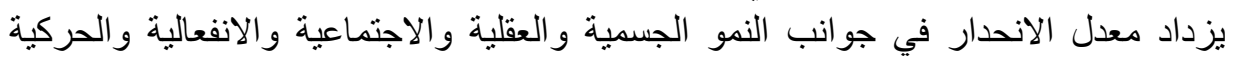

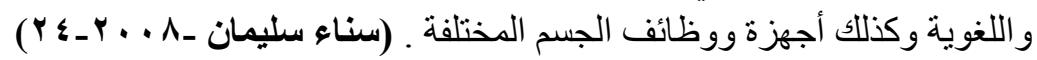

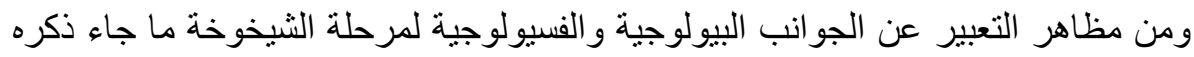

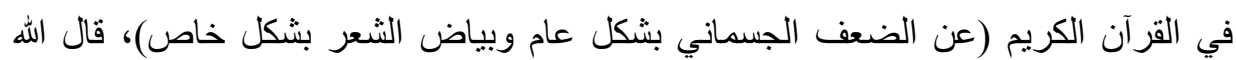

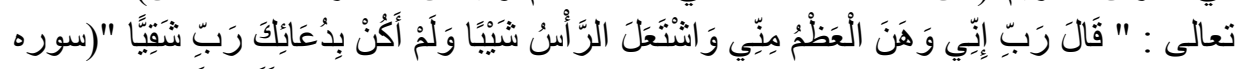

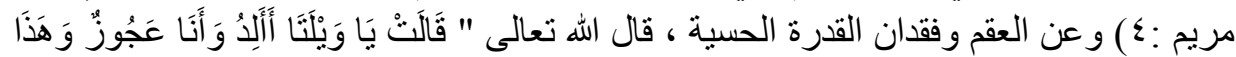

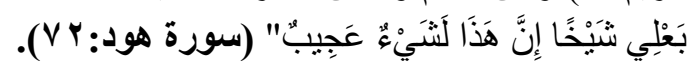

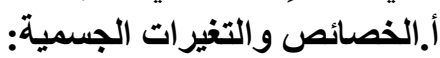

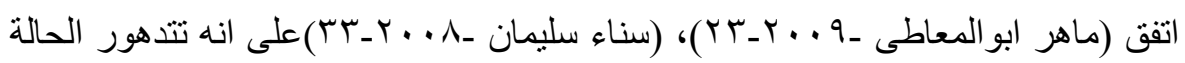

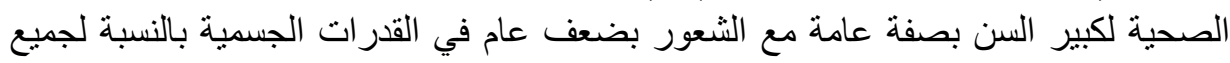

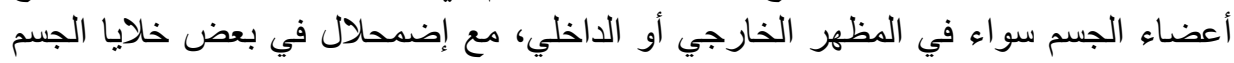

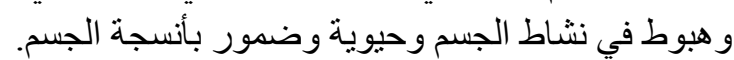

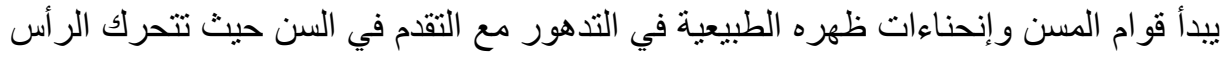

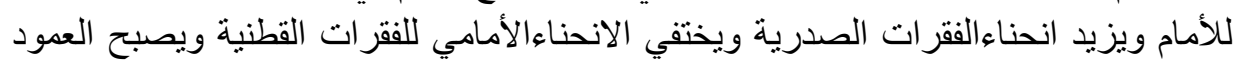

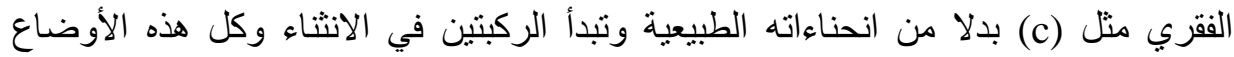

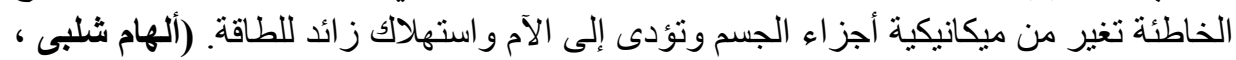

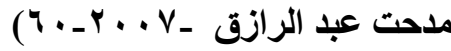

$$
\begin{aligned}
& \text { ا ـ تغيرات في الجهاز الجلدي: }
\end{aligned}
$$

، بظهر التجعيد والطيات والأخاديد و البرقثة ( بقع ملونه ) ويعنى كبير السن من جفاف الجلد

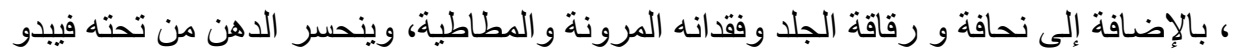

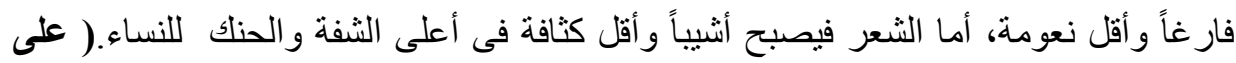

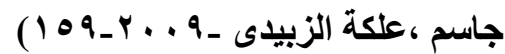

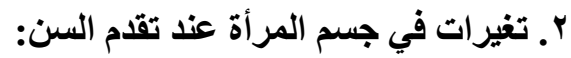

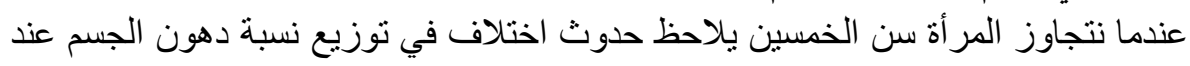

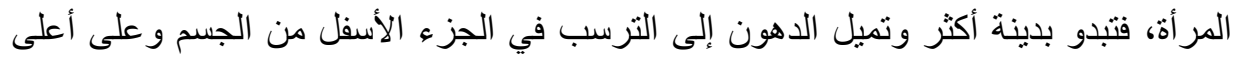

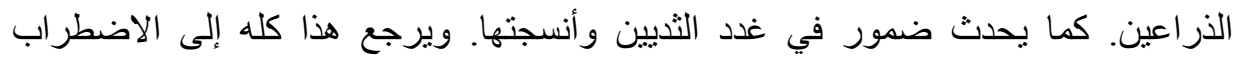

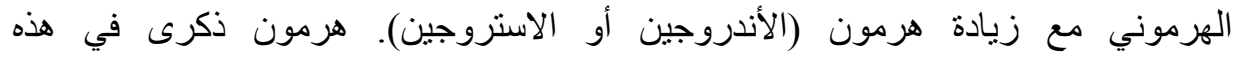

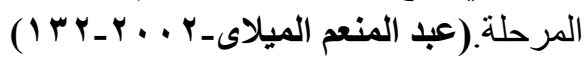




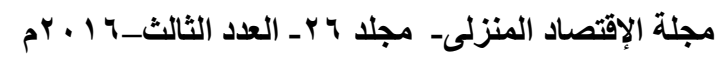

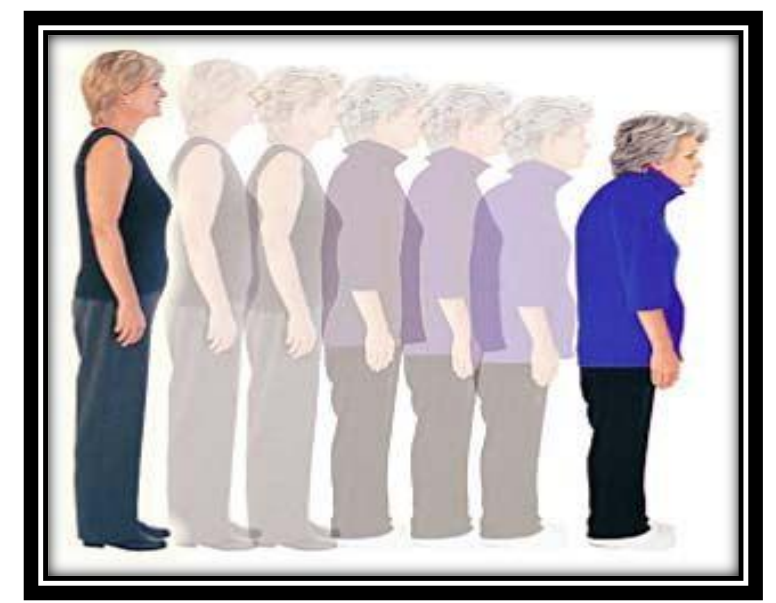

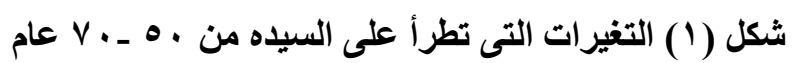
www.niroonnews.com/9/2014.

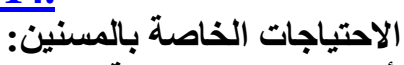

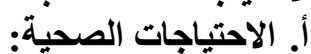

يحتاج المسنون إلي الرعاية الصحية وذللك لضعف قوتهم وقدرتهم الجسمية و إصابة بعضهم

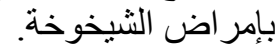
ج. الاحتياجات الاقتصادية:

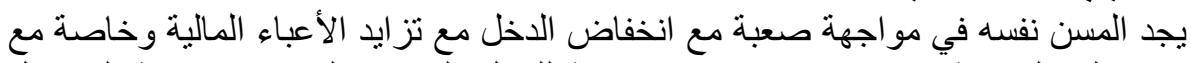

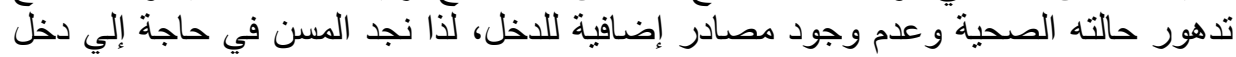

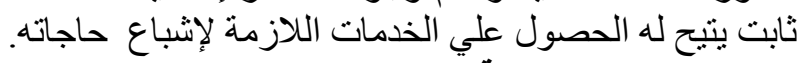

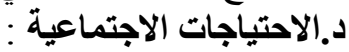

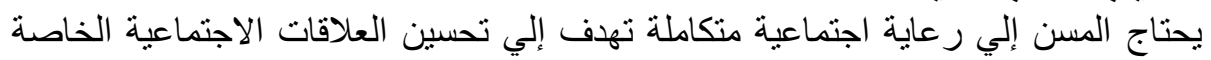

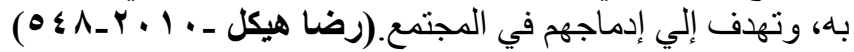

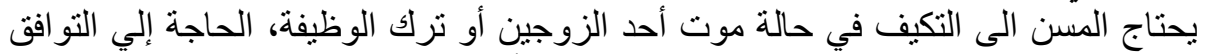

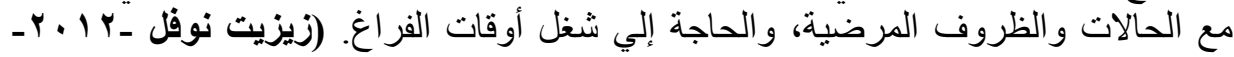

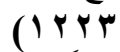
أولاً: الأمر اض اضك التى تصيب كبار السن

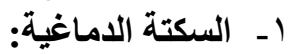

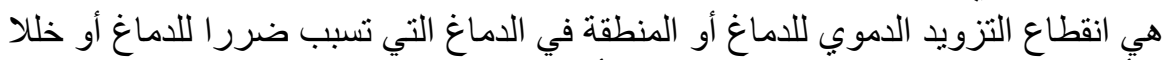

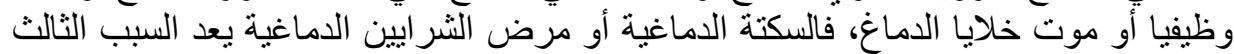

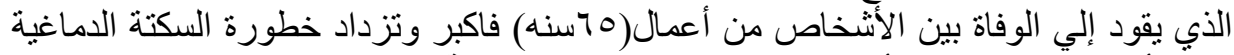

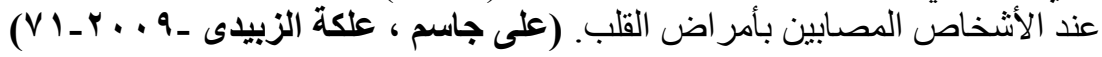




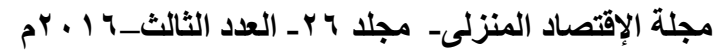

كما تتعدد الأسباب المؤدية للسكتة الاماغية منها:

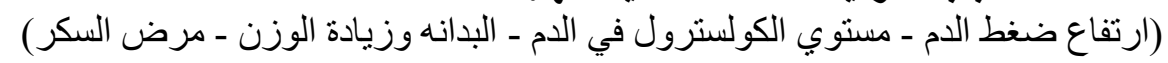

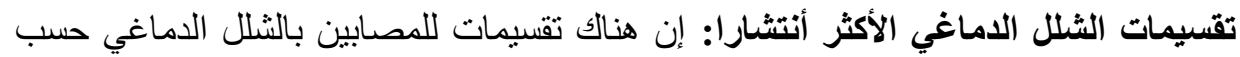

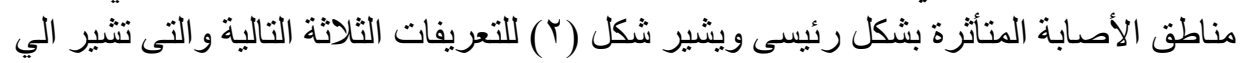

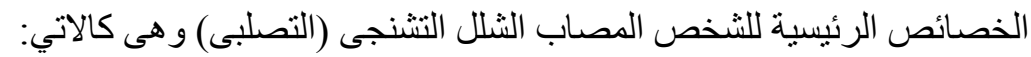

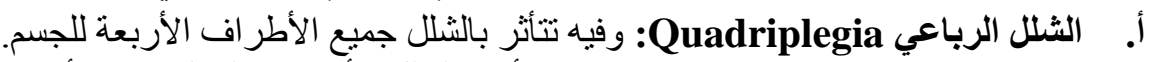

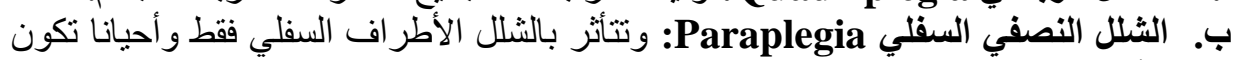

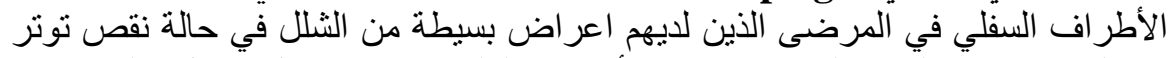
عضلي نسبي في الوقت الذي تؤدي فيه الأطر اف العليا وظيفتها بشكل افضل والفي الذي يمكن

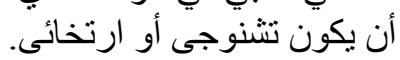

الثلل النصفي الجانبي:Said Hemiplegia: ينأثر بالثلل جانب واحد فقط من الجسم متضمنا

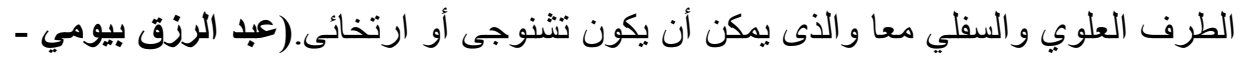

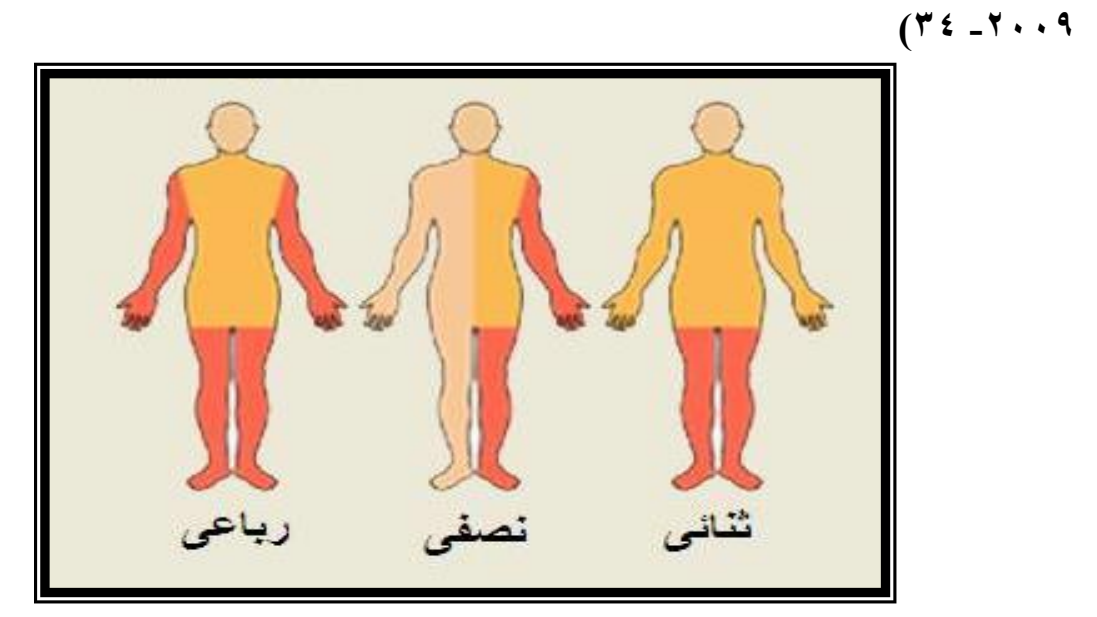

شكل (r) أنواع الثنلل الدماغى

http://www.jormedic.com/index.php/articles/12/201

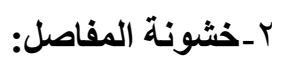

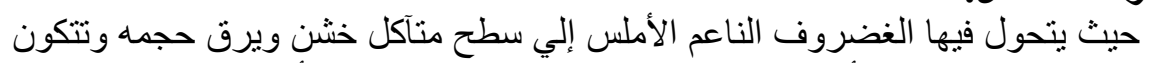

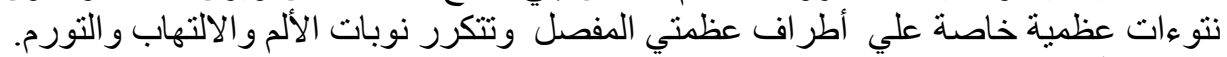

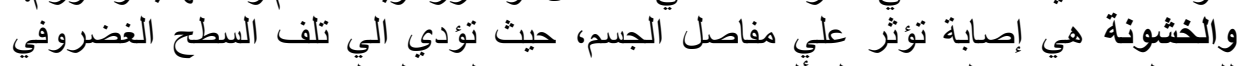

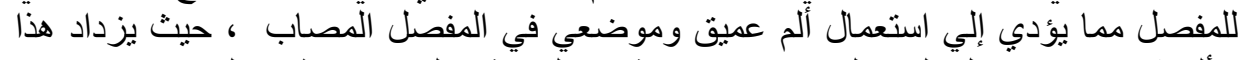

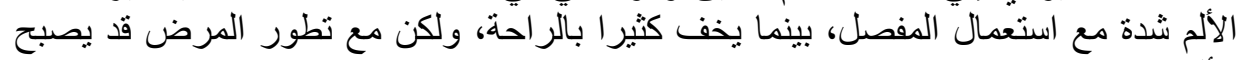

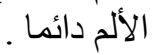


مجلة الإقتصاد المنزلى- مجلد 7 ـ العدد الثالث_r 1 • ب م

المفاصل التى تصاب بالخشونة:

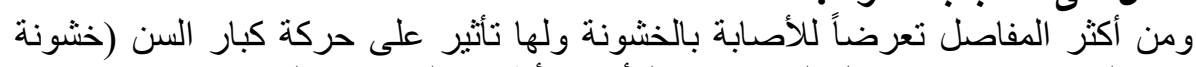

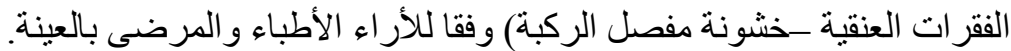
WWW.isom.com

أ. شثونة مفصل الركبة: تركيب الركبة: تتكون الركبة من عظملة الركة الفخذ و عظمة القصبة وبينهما غضاريف واربطه كما

موضح بشكل (ب).

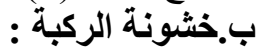
تسمى تأكل غضروف الركبة الركة وهو مرض بنتج عن تأكل الغضاريف الناعمة التي تلامس سطح

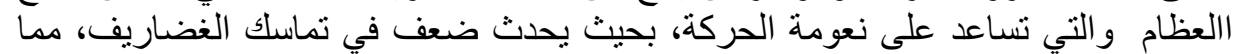

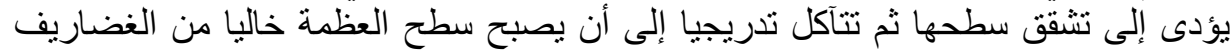

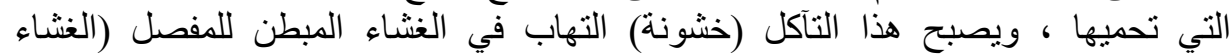

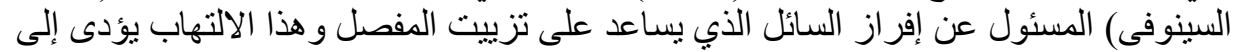

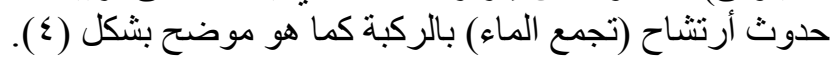

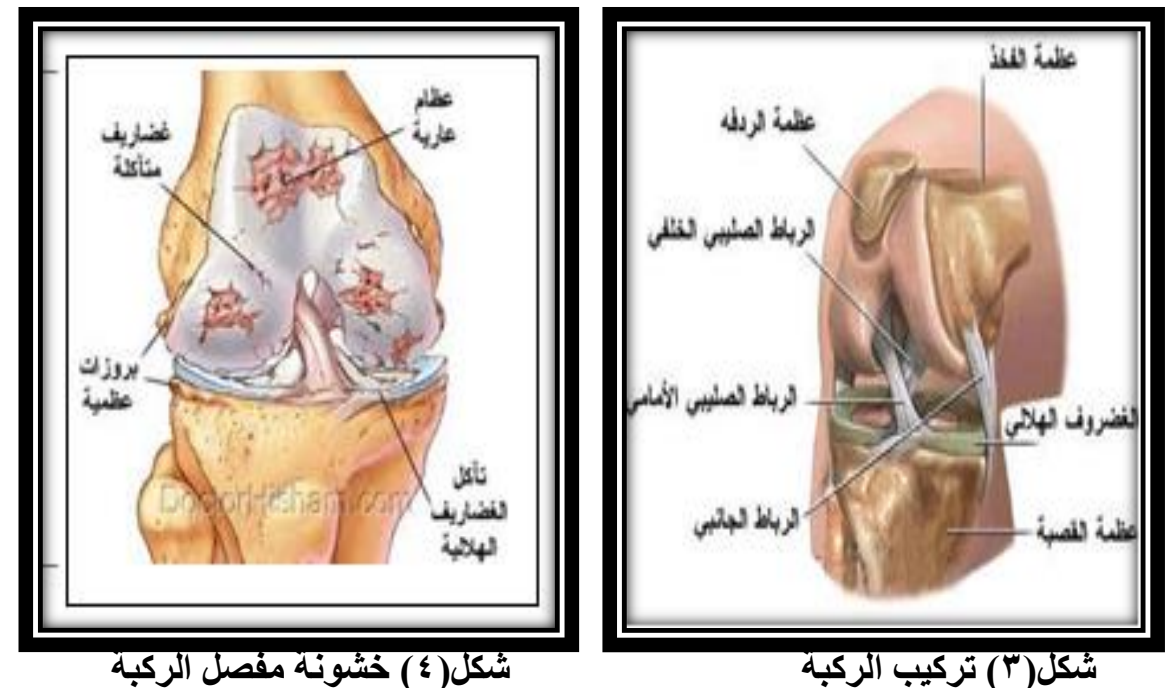

http://www.al-health.net/3/2016http://romance-love.ws

ويعتبر خشونة مفصل الركبة أحد أهم إصابات الإعاقة مع تقدم السن ولاى الثباب

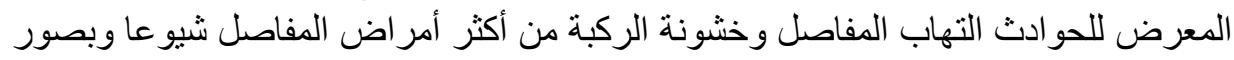

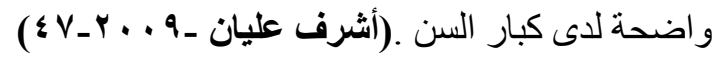

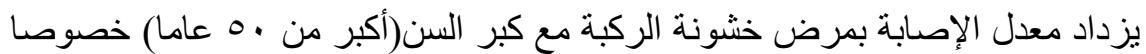

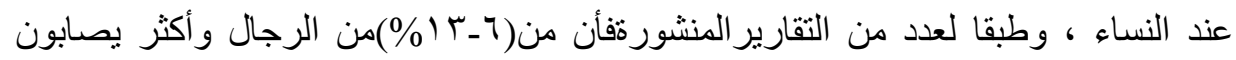

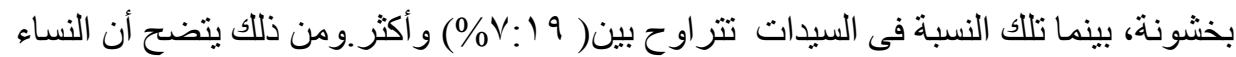

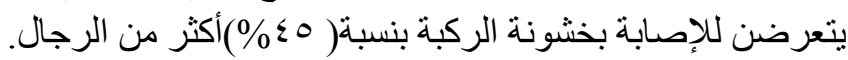


أهمية الملابس للفئات الخاصة من كبار السن مرضي الروماتويد - خشونه المفاصل) :

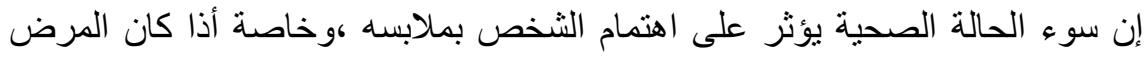

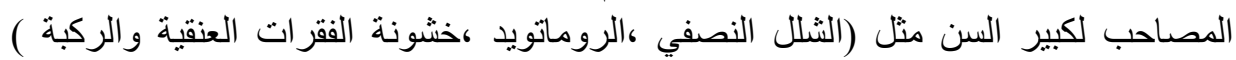

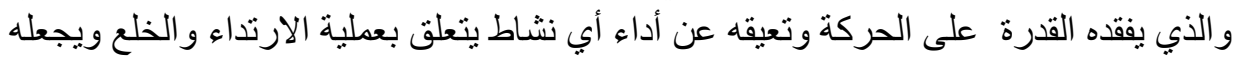

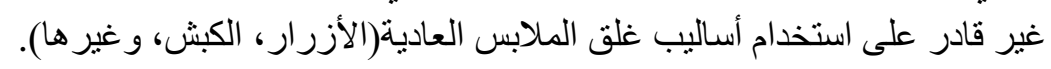

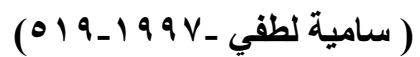

كما يؤثر سوء الحالة الصحية تأثير على النواحي النفسي، فبعضهم يغلب علية الخجل

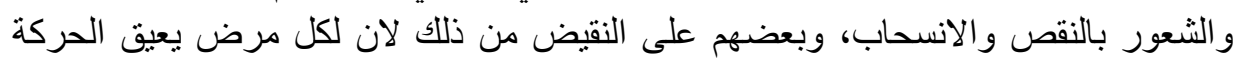

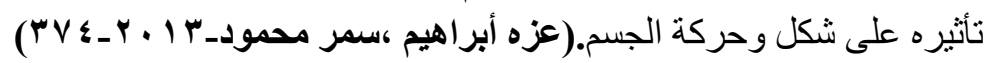
الاطار التطبيقى : التيره

إن إعداد تصميمات لملابس الفئات الخاصة من السيدات كبار السن المصابين بمرض النيات

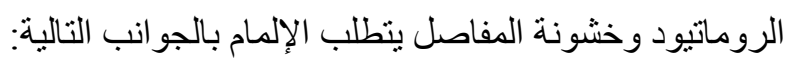
• العوامل المؤثرة على تصميموتنفيذ ملابس الفئات الخاصة لمرضي الرئة الروماتويد وخشونة المفاصل ه المنطلبات الملبسية للفئات الخاصة من كبار السن المصابين بالروماتيود وخثونة

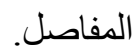
الخصائص والتغيرات التي تطرأ على مرضي الروماتويد وخثونة المفاصلو علاقتها بالملابس

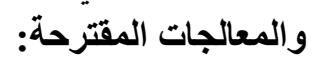

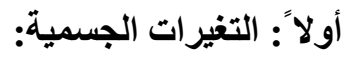
1- يواجه قصور وضعف في التحكم العضلي ، مع نقص في قدرتة على القبض على علي الأثياء

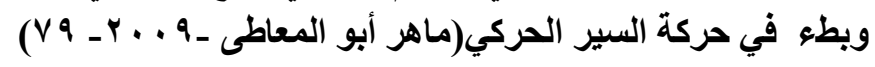

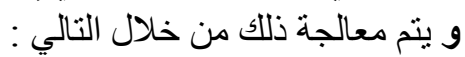
- التصميم: حيث ير اعى استخدام الفتحات الأمامية و تجنب استخدام الازار و الكبش ويفضل

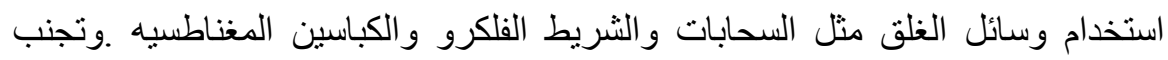
الملابس شديدة الاتساع والضيقة التي بدون توسيع خاصة في خط الثط الذيل لأنها تعرقل

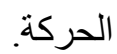
r- يزيد انحناء الفقرات الصدرية ويختفي الانحناء الأمامي للفقرات القطنية ويصبح العمود

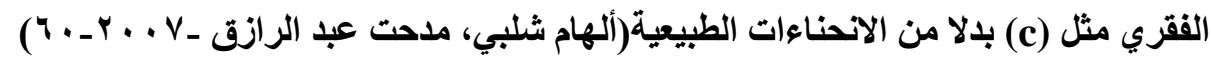

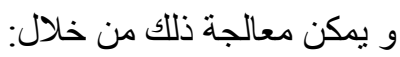

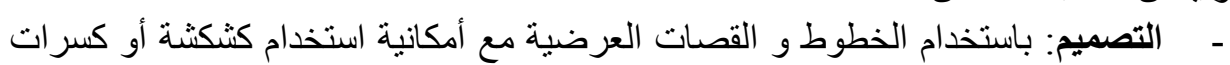
مع هذه القصة و تصميم الملابس واسعة نسبيا و على أن تكون المعان الملابس (الانسامبل) مكونة في قطعتين. 


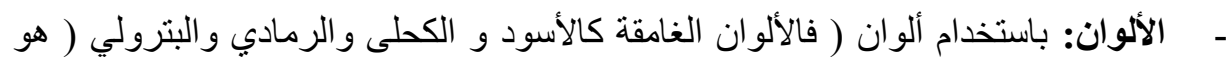

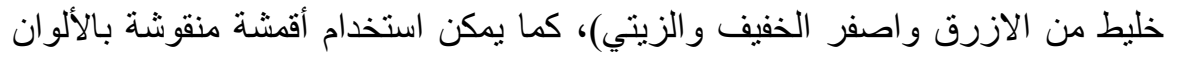

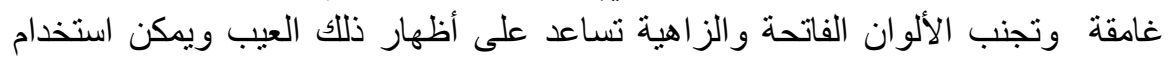

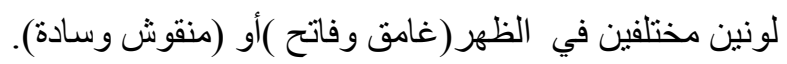

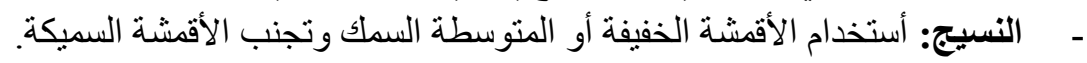

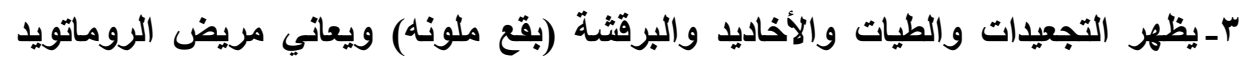

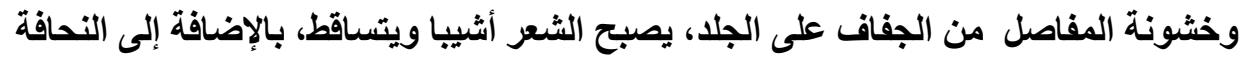

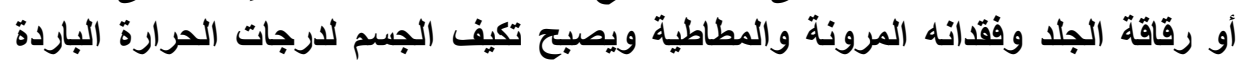

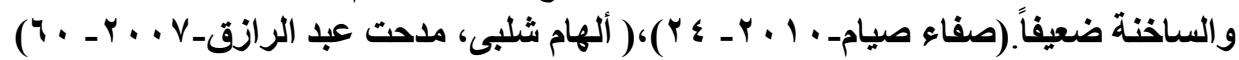

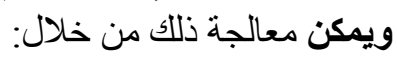

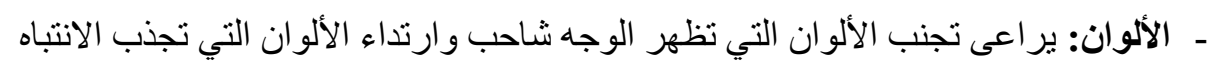

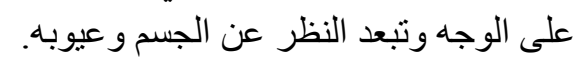

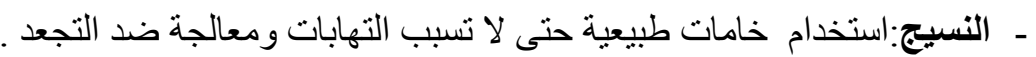

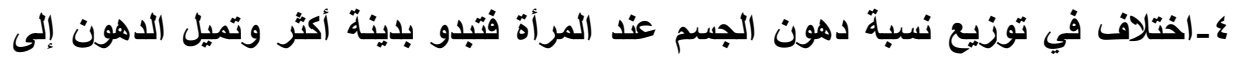

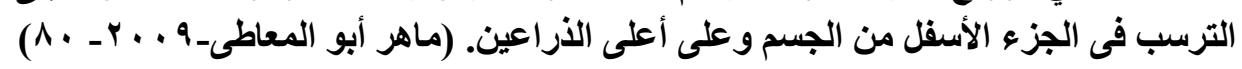

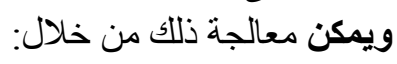
- - التصميم:استخدام الأكتاف المحددة مع إضافة توسيع لحردة الإبط وذللك لتحقيق الراحة،

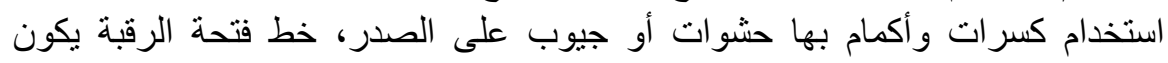

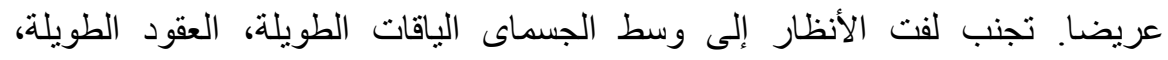

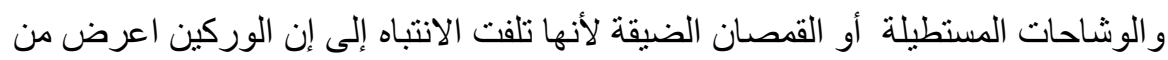

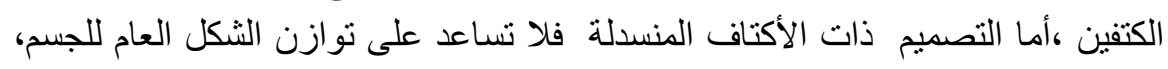

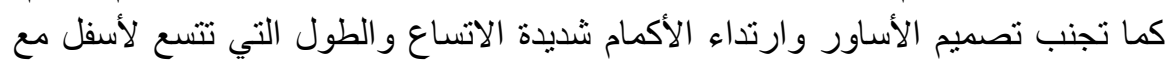
حردة رقبة منسعة.

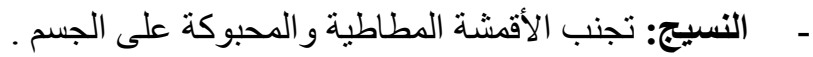

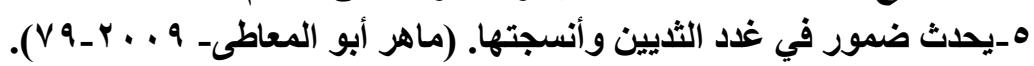

$$
\begin{aligned}
& \text { ويمكن معالجة ذللك من خلال: }
\end{aligned}
$$

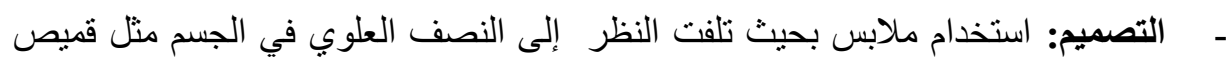

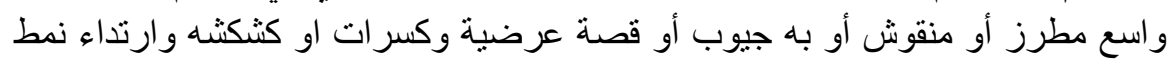
الملبس (الانسامبل) المكون في قطعتين ينزلق على الفى الجسم. - الألوان: الثياب العلوية لون فاتح عن الذي أسفلها. 


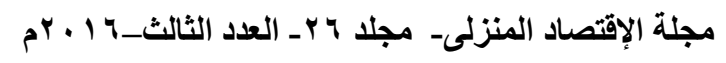

ثانياً :-التغير ات النفسية والافر اط المادى:

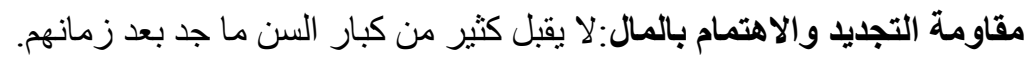

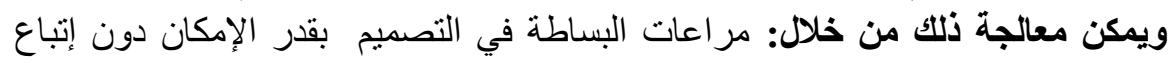

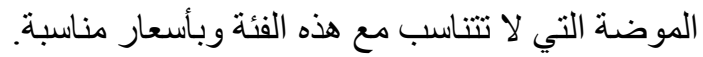

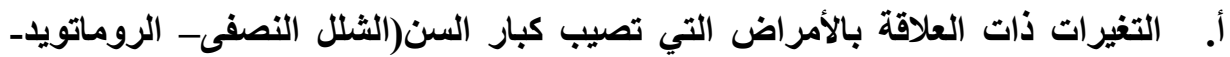
خثونة الفقرات العنقية والركبة) و وعلاقتها بالملابس.

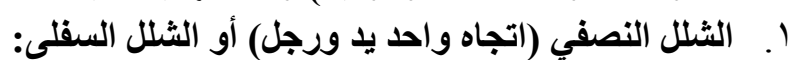

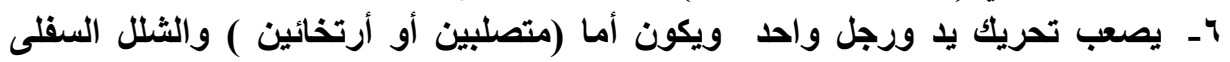

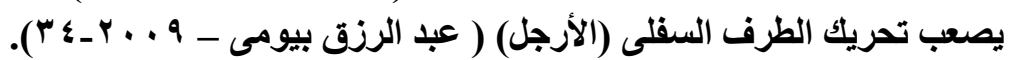
و يتم معالجة ذلكمن خلال : - التصميم :يراعى اتجاهات الفتحات التي تساعد على تسهيل عملية الارتداء وتنكون في

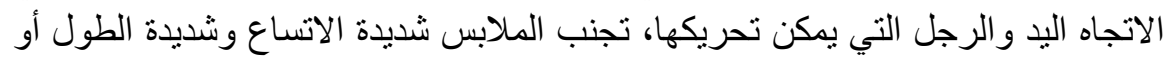

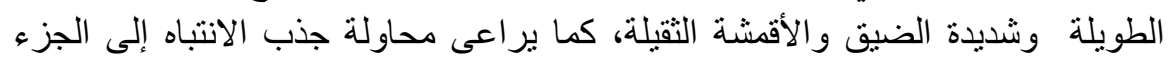

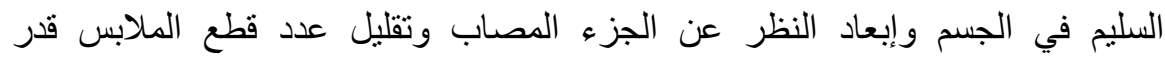
الإمكان،تجنب الموثقات التي تتطلب التنسيق بين كلا اليدين ، فيمكن استخدام الموثقات الئن

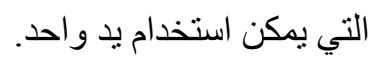
V- الاكتئاب النفسي والانغلاق على الذات: يمكن تحسين هذه الحالة عن طريق اختيار ملابس

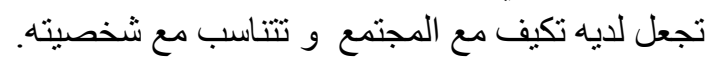
r. مرض خثونة الرقبة والروماتيد: - ألم في الرقبة وعدم القدرة على تحريكها

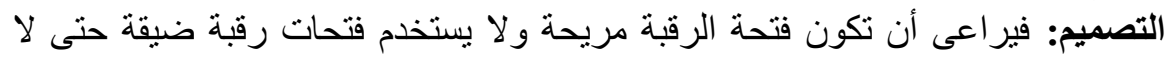

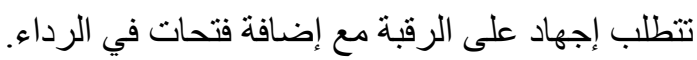
- ـ - نسيج: استخدام النسيج اللين الذى يحنوى على نسبة من المطاطية وتجنب الأقمشة قليلة

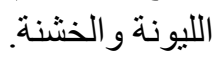

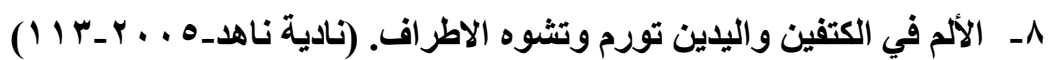

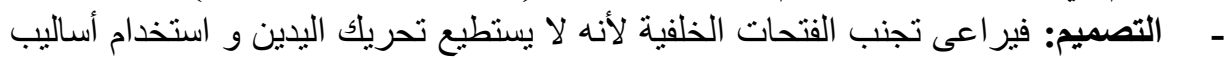

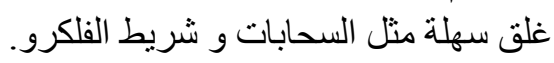

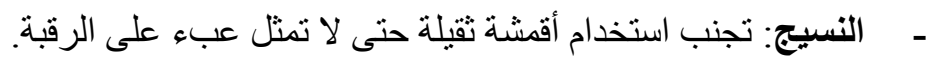

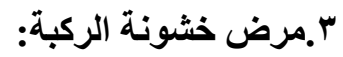

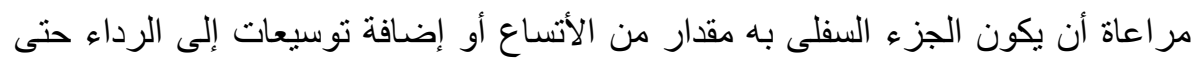

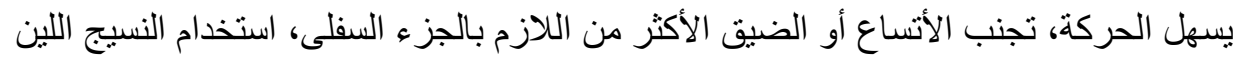
الذي يحتوى على نسبة من المطاطية. 
مجلة الإقتصاد المنزلى- مجلد 7 ـ العدد الثالث_r 1 • ب م

التصميمات المقترحة :

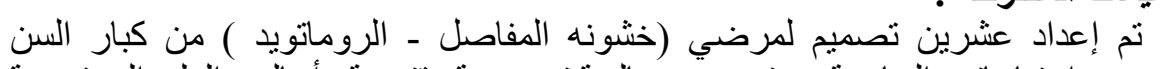

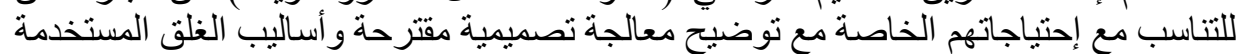

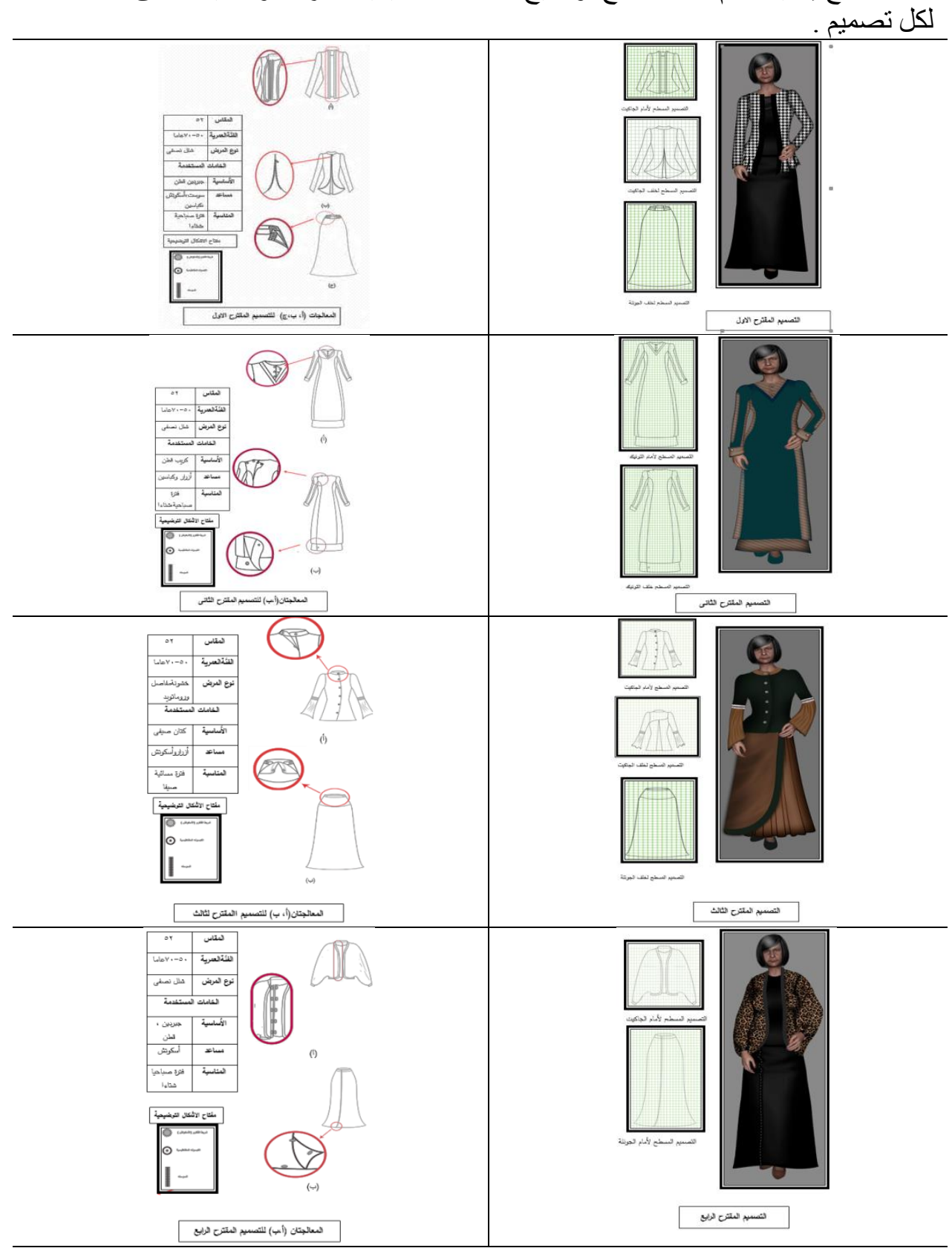




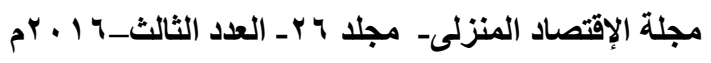

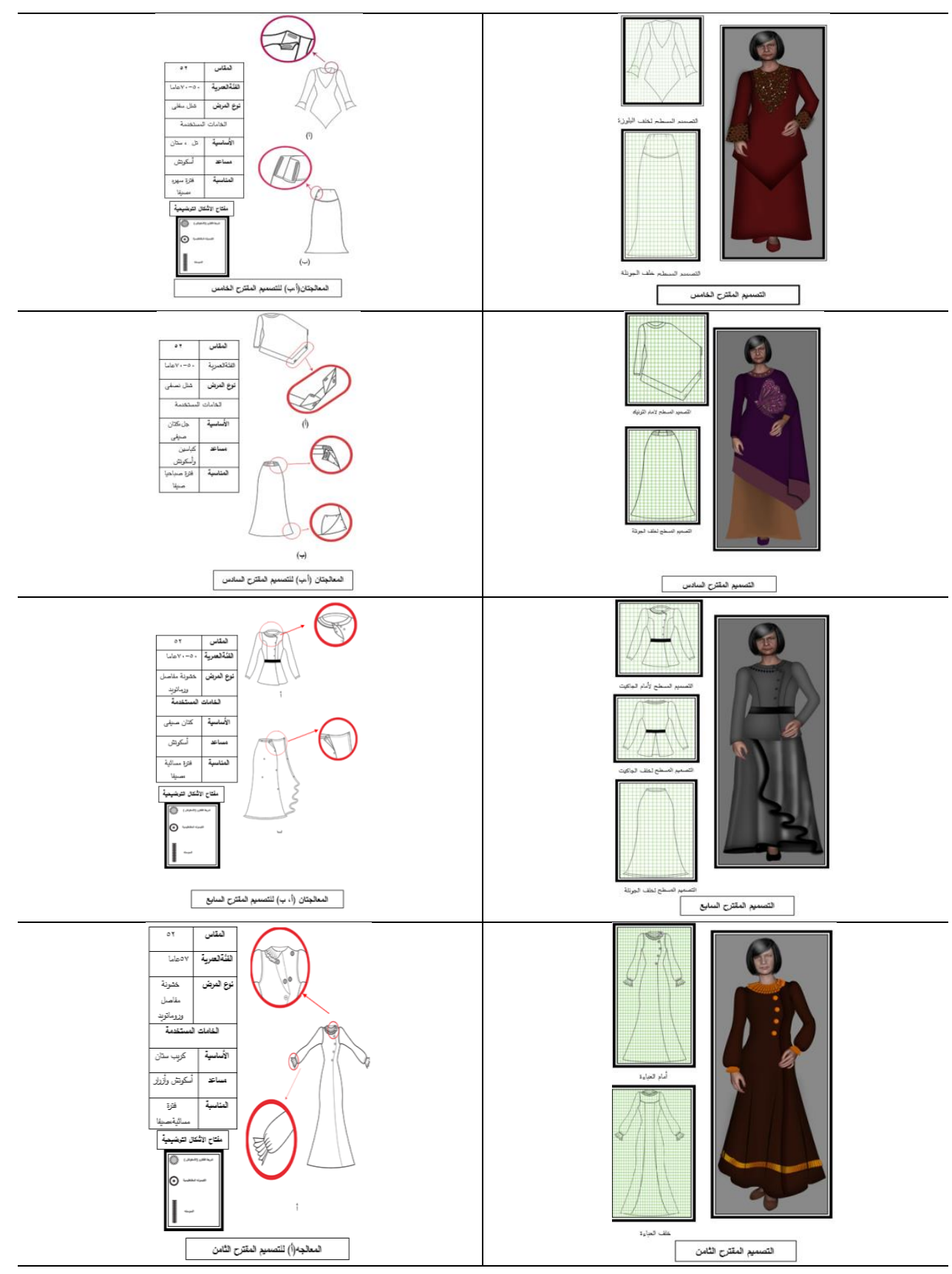




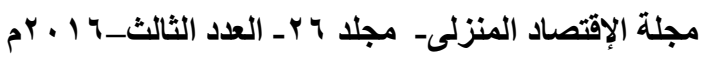

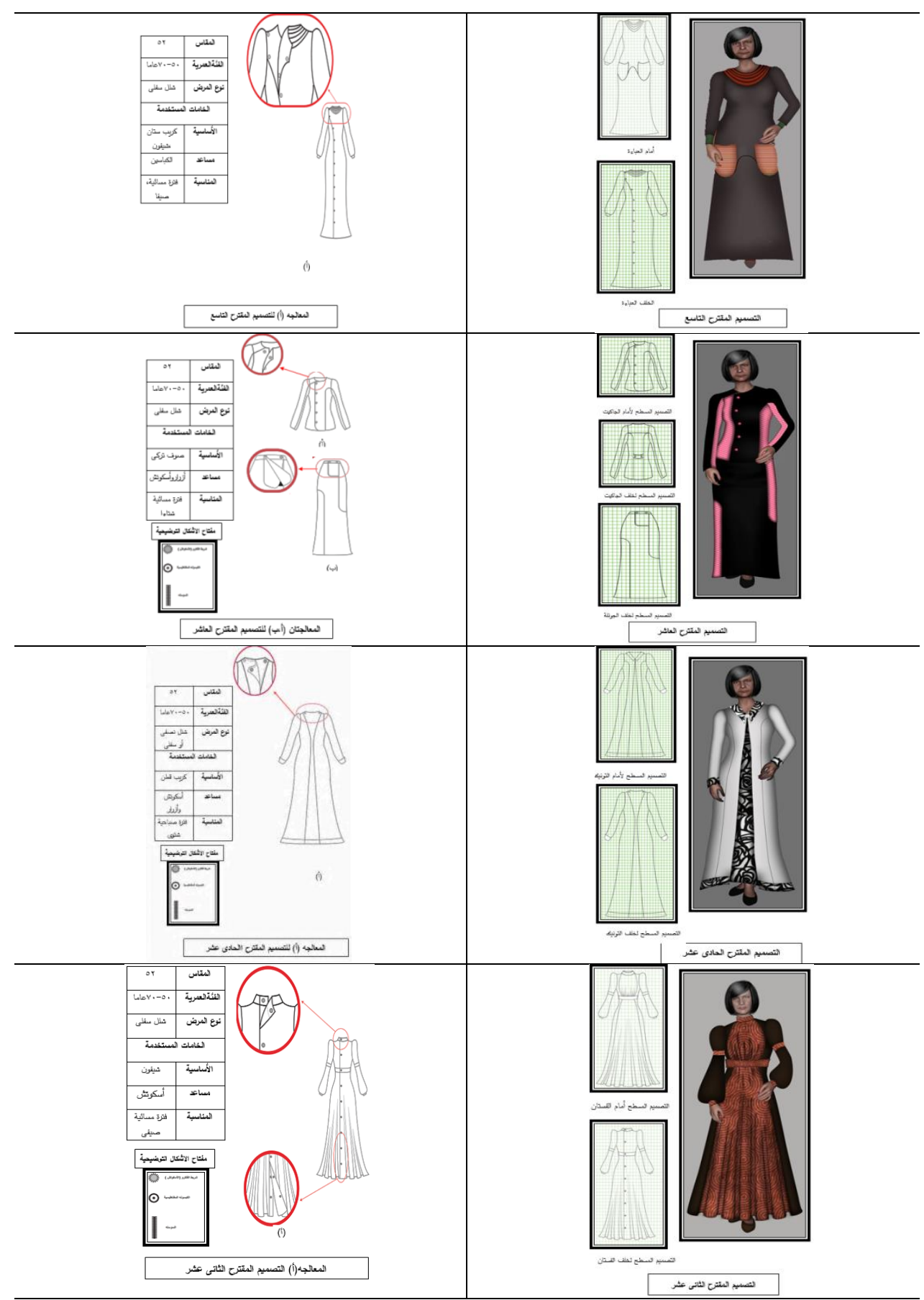




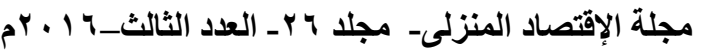

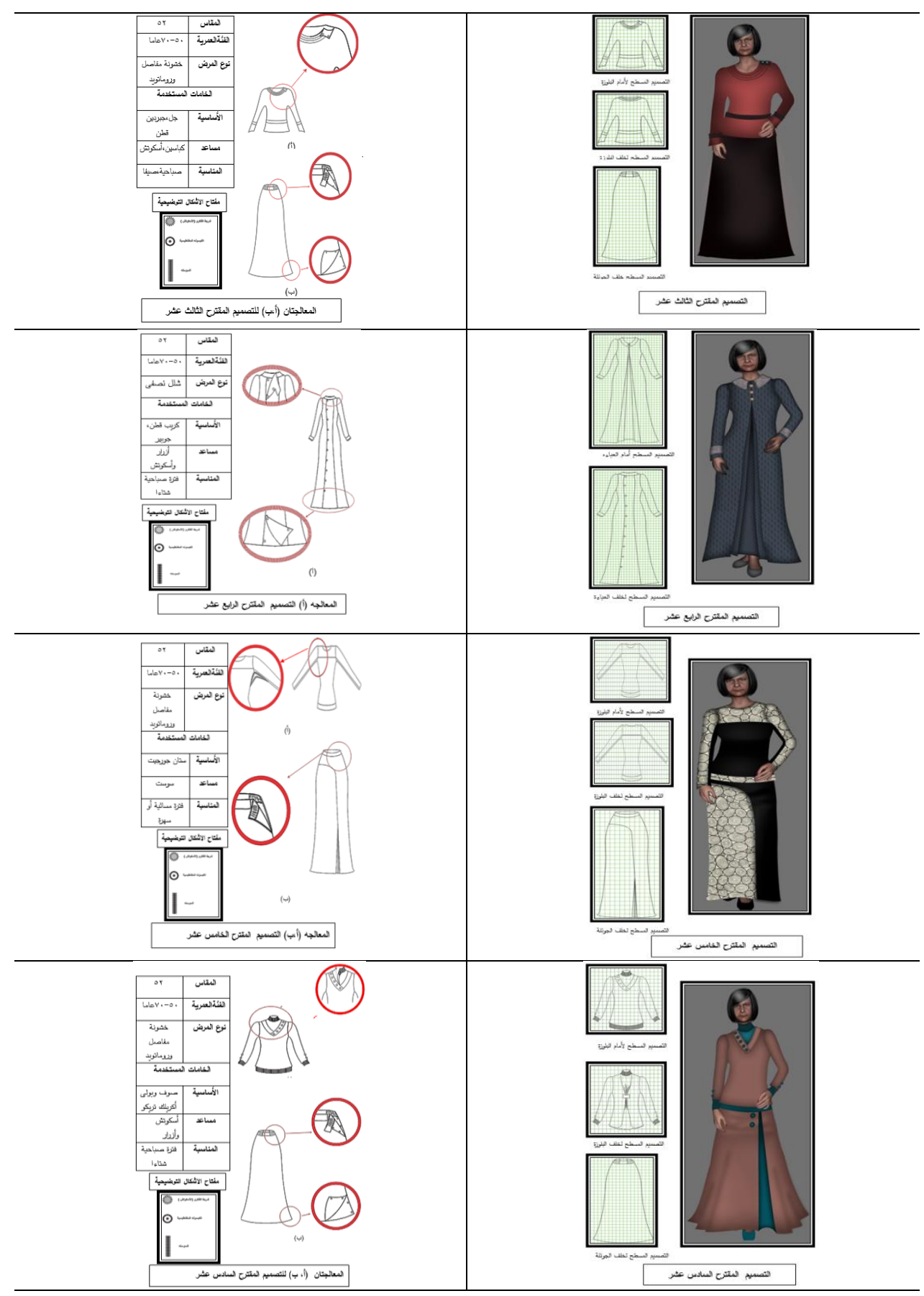




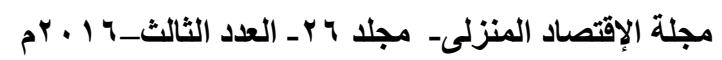

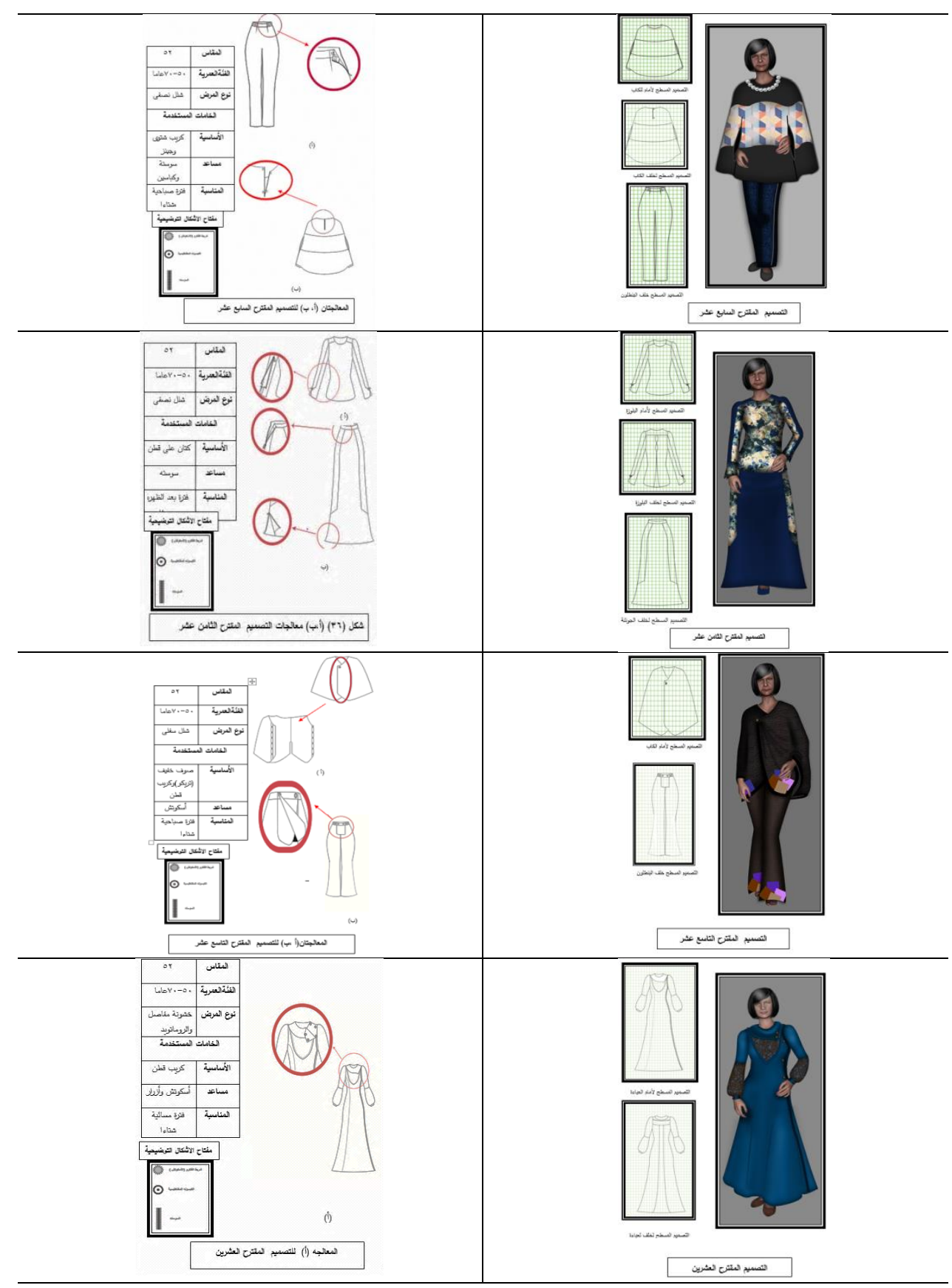

PIq 


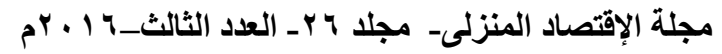

بعد إعداد التصميمات المقترحة تم عرض التصميمات للتقييم من قبل كلاً من :

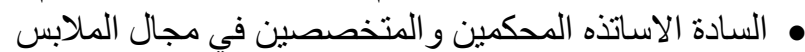

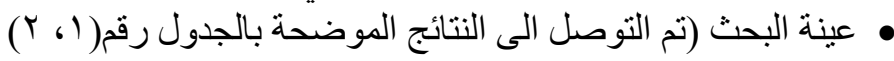

جدول( 1) الوزن النسبي لكل تصميم من التصميمات وفقا لأراء السادة المحكمين

\begin{tabular}{|c|c|c|c|c|c|c|c|c|c|c|c|}
\hline \multirow{2}{*}{ الترتيب } & \multirow{2}{*}{ |للمتوسئة المونة } & \multirow[b]{2}{*}{ لموزون } & \multirow[b]{2}{*}{ المجموع } & \multicolumn{5}{|c|}{ مستويات القياس } & \multirow{2}{*}{\multicolumn{2}{|c|}{ العينة }} & \multirow[b]{2}{*}{ التصميم } \\
\hline & & & & ضعيف & مقبول & جيا & جيا جدأ & ممتاز & & & \\
\hline \multirow{2}{*}{5} & \multirow{2}{*}{84.5} & 1774 & 420 & 4 & 12 & 65 & 144 & 195 & 5 & \multirow{2}{*}{$\begin{array}{l}=\dot{U} \\
Y\end{array}$} & \multirow{2}{*}{1} \\
\hline & & 4.2 & 100 & 0.8 & 2.4 & 12.9 & 28.5 & 38.6 & $\%$ & & \\
\hline \multirow{2}{*}{10} & \multirow{2}{*}{80.6} & 1693 & 420 & 12 & 28 & 52 & 171 & 157 & 5 & \multirow{2}{*}{$\begin{array}{l}=\dot{U} \\
Y\end{array}$} & \multirow{2}{*}{ r } \\
\hline & & 4.0 & 100 & 2.4 & 5.5 & 10.3 & \begin{tabular}{|l|}
33.9 \\
\end{tabular} & 31.1 & $\%$ & & \\
\hline \multirow{2}{*}{17} & \multirow{2}{*}{70.0} & 1469 & 420 & 6 & 71 & 138 & 118 & 87 & S & \multirow{2}{*}{$\begin{array}{l}=\dot{u} \\
Y\end{array}$} & \multirow{2}{*}{$r$} \\
\hline & & 3.5 & 100 & 1.2 & 14.1 & 27.3 & \begin{tabular}{|l|}
23.4 \\
\end{tabular} & 17.2 & $\%$ & & \\
\hline \multirow{2}{*}{8} & \multirow{2}{*}{83.2} & \begin{tabular}{|l|l}
1748 \\
\end{tabular} & 420 & 15 & 14 & 29 & 192 & 170 & ك & \multirow{2}{*}{$\begin{array}{l}=\dot{ } \\
Y\end{array}$} & \multirow{2}{*}{ 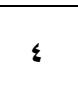 } \\
\hline & & 4.2 & 100 & 3.0 & 2.8 & 5.7 & 38.0 & 33.7 & $\%$ & & \\
\hline \multirow{2}{*}{1} & \multirow{2}{*}{90.0} & 1890 & 420 & 0 & 5 & 43 & 109 & 263 & ك & \multirow{2}{*}{$\begin{array}{l}=\dot{ } \\
r_{1}\end{array}$} & \multirow{2}{*}{0} \\
\hline & & 4.5 & 100 & 0.0 & 1.0 & 8.5 & \begin{tabular}{|l|}
21.6 \\
\end{tabular} & 52.1 & $\%$ & & \\
\hline 7 & 841 & \begin{tabular}{|l|l}
1766 \\
\end{tabular} & 420 & 3 & 6 & 59 & 186 & 166 & ك & ن & 7 \\
\hline t & 84.1 & 4.2 & 100 & 0.6 & 1.2 & 11.7 & 36.8 & 32.9 & $\%$ & $r$ & 1 \\
\hline 14 & 731 & \begin{tabular}{|l|l}
1536 \\
\end{tabular} & 420 & 0 & 73 & 106 & 133 & 108 & 5 & ن & $y$ \\
\hline 14 & 13.1 & 3.7 & 100 & 0.0 & 14.5 & 21.0 & \begin{tabular}{|l|}
26.3 \\
\end{tabular} & 21.4 & $\%$ & $r$ & \\
\hline 11 & 757 & 1590 & 420 & 24 & 48 & 73 & 124 & 151 & S & ن & $\Lambda$ \\
\hline 11 & 15.1 & 3.8 & 100 & 4.8 & 9.5 & 14.5 & 24.6 & 29.9 & $\%$ & YI & \\
\hline 18 & $66 ?$ & 1390 & 420 & 17 & 73 & 153 & 117 & 60 & S & ن & 9 \\
\hline 18 & 66.2 & 3.3 & 100 & 3.4 & 14.5 & 30.3 & \begin{tabular}{|l|}
23.2 \\
\end{tabular} & 11.9 & $\%$ & r & 9 \\
\hline 0 & 617 & 1295 & 420 & 62 & 65 & 139 & 84 & 70 & S & ن & 1. \\
\hline 20 & 61.1 & 3.1 & 100 & 12.3 & 12.9 & 27.5 & \begin{tabular}{|l|}
16.6 \\
\end{tabular} & 13.9 & $\%$ & Y & \\
\hline 6 & 04 & 1773 & 420 & 1 & 0 & 75 & 173 & 171 & ك & ن & , \\
\hline 0 & 84.4 & 4.2 & 100 & 0.2 & 0.0 & 14.9 & 34.3 & 33.9 & $\%$ & 1 & 11 \\
\hline 10 & 643 & 1351 & 420 & 19 & 108 & 93 & 163 & 37 & 5 & ن & IY \\
\hline 19 & 64.3 & 3.2 & 100 & 3.8 & 21.4 & 18.4 & \begin{tabular}{|l|}
32.3 \\
\end{tabular} & 7.3 & $\%$ & 1 & $\pi$ \\
\hline 16 & 704 & $\mid 1478$ & 420 & 38 & 18 & 147 & 122 & 95 & ك & ن & $\mu$ \\
\hline 10 & 10.4 & 3.5 & 100 & 7.5 & 3.6 & 29.1 & \begin{tabular}{|l|l|}
24.2 \\
\end{tabular} & 18.8 & $\%$ & $r$ & 11 \\
\hline 4 & 850 & 1785 & 420 & 0 & 9 & 68 & 152 & 191 & S & ن & 14 \\
\hline 4 & 85.0 & 4.3 & 100 & 0.0 & 1.8 & 13.5 & 30.1 & 37.8 & $\%$ & $r$ & 12 \\
\hline 0 & 800 & 1679 & 420 & 13 & 0 & 111 & 147 & 149 & ك & ن & 10 \\
\hline 9 & 80.0 & 4.0 & 100 & 2.6 & 0.0 & 22.0 & 29.1 & 29.5 & $\%$ & $r 1$ & 10 \\
\hline
\end{tabular}




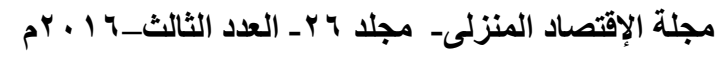

\begin{tabular}{|c|c|c|c|c|c|c|c|c|c|c|c|}
\hline \multirow{2}{*}{ الترتيب } & \multirow{2}{*}{ المئوسئة } & \multirow{2}{*}{ |(الموزون| } & \multirow[b]{2}{*}{ لمجموع } & \multicolumn{5}{|c|}{ مستويات القياس } & \multirow{2}{*}{\multicolumn{2}{|c|}{ العينة }} & \multirow{4}{*}{ التصمي } \\
\hline & & & & \multirow{2}{*}{ ضعيف } & \multirow{2}{*}{ مقبول } & \multirow{2}{*}{ جي } & \multirow{2}{*}{ جيل جداً } & \multirow{2}{*}{ ممتاز } & & & \\
\hline \multirow{2}{*}{12} & \multirow{2}{*}{74.2} & 1559 & 420 & & & & & & s & \multirow{2}{*}{$\begin{array}{l}=\dot{0} \\
r 1\end{array}$} & \\
\hline & & 3.7 & 100 & 2.2 & 7.7 & 23.6 & 28.1 & 21.6 & $\%$ & & \\
\hline \multirow{2}{*}{3} & \multirow{2}{*}{86.3} & 1813 & 420 & 20 & 25 & 33 & 66 & 276 & S & \multirow{2}{*}{$\begin{array}{l}=\dot{u} \\
r 1\end{array}$} & \multirow{2}{*}{ IV } \\
\hline & & 4.3 & 100 & 4.0 & 5.0 & 6.5 & 13.1 & 54.7 & $\%$ & & \\
\hline \multirow{2}{*}{13} & \multirow{2}{*}{74.1} & 1556 & 420 & 0 & 47 & 157 & 89 & 127 & S & \multirow{2}{*}{$\begin{array}{l}=\dot{U} \\
r 1\end{array}$} & \multirow{2}{*}{11} \\
\hline & & 3.7 & 100 & 0.0 & 9.3 & 31.1 & 17.6 & 25.1 & $\%$ & & \\
\hline \multirow{2}{*}{15} & \multirow{2}{*}{70.8} & 1486 & 420 & 41 & 36 & 118 & 106 & 119 & ك & \multirow{2}{*}{$\begin{array}{l}=\dot{U} \\
r 1\end{array}$} & \multirow{2}{*}{19} \\
\hline & & 3.5 & 100 & 8.1 & 7.1 & 23.4 & 21.0 & 23.6 & $\%$ & & \\
\hline \multirow{4}{*}{2} & \multirow{2}{*}{87.9} & 1846 & 420 & 2 & 17 & 28 & 139 & 234 & ك & \multirow{2}{*}{$\begin{array}{l}=\dot{U} \\
r 1\end{array}$} & \multirow[t]{2}{*}{$r}$. \\
\hline & & 4.4 & 100 & 0.4 & 3.4 & 5.5 & 27.5 & 46.3 & $\%$ & & \\
\hline & \multirow{2}{*}{77.3} & 32454 & 8400 & 265 & 694 & 1806 & 2677 & 2935 & S & \multirow{2}{*}{$\begin{array}{l}=\dot{0} \\
r 1\end{array}$} & \multirow{2}{*}{ الاجمالم } \\
\hline & & 3.9 & 100 & 3.2 & 8.3 & 21.5 & 31.9 & 34.9 & $\%$ & & \\
\hline
\end{tabular}

جدول(r) الوزن النسبي لكل تصميم من التصميمات وفقا لار اء الفئات الخاصة من عينه البحث

\begin{tabular}{|c|c|c|c|c|c|c|c|c|c|c|c|}
\hline \multirow[b]{2}{*}{ الترتيب } & \multirow{2}{*}{ اللمتوسئ النسبة } & \multirow{2}{*}{ لموزون } & \multirow[b]{2}{*}{ |المجموع } & \multicolumn{5}{|c|}{ مستويات القياس } & \multirow{2}{*}{\multicolumn{2}{|c|}{ العينة }} & \multirow[b]{2}{*}{ التصميم } \\
\hline & & & & ضعيف & مقبول & جيد & جيد جدا & ممتاز & & & \\
\hline \multirow{2}{*}{3} & \multirow{2}{*}{88} & 4400 & 1000 & 0 & 22 & 130 & 274 & 574 & ك & \multirow{2}{*}{$\begin{array}{l}=\dot{0} \\
.\end{array}$} & \multirow{2}{*}{1} \\
\hline & & 4.4 & 100 & 0.0 & 1.8 & 10.4 & 21.9 & 45.9 & $\%$ & & \\
\hline \multirow{2}{*}{12} & \multirow{2}{*}{69.64} & 3482 & 1000 & 0 & 202 & 252 & 408 & 138 & S & \multirow{2}{*}{$\begin{array}{l}=\dot{0} \\
\text { ○. }\end{array}$} & \multirow{2}{*}{ r } \\
\hline & & 3.5 & 100 & 0.0 & 16.2 & 20.2 & 32.6 & 11.0 & $\%$ & & \\
\hline \multirow{2}{*}{20} & \multirow{2}{*}{62.68} & 3134 & 1000 & 30 & 258 & 352 & 268 & 92 & 5 & \multirow{2}{*}{$\begin{array}{l}=\dot{ } \\
0 .\end{array}$} & \multirow{2}{*}{$r$} \\
\hline & & 3.1 & 100 & 2.4 & 20.6 & 28.2 & 21.4 & 7.4 & $\%$ & & \\
\hline \multirow{2}{*}{9} & \multirow{2}{*}{70.48} & 3524 & 1000 & 52 & 164 & 186 & 404 & 194 & s & \multirow{2}{*}{$\begin{array}{l}=\text { '. } \\
\text { o. }\end{array}$} & \multirow{2}{*}{$\varepsilon$} \\
\hline & & 3.5 & 100 & 4.2 & 13.1 & 14.9 & 32.3 & 15.5 & $\%$ & & \\
\hline \multirow{2}{*}{5} & \multirow{2}{*}{85.08} & 4254 & 1000 & 0 & 62 & 110 & 340 & 488 & S & \multirow{2}{*}{$\begin{array}{l}=\dot{0} \\
0 .\end{array}$} & \multirow{2}{*}{0} \\
\hline & & 4.3 & 100 & 0.0 & 5.0 & 8.8 & 27.2 & 39.0 & $\%$ & & \\
\hline \multirow{2}{*}{16} & \multirow{2}{*}{66.68} & 3334 & 1000 & 6 & 184 & 380 & 330 & 100 & S & \multirow{2}{*}{$\begin{array}{l}=\dot{0} \\
0 .\end{array}$} & \multirow{2}{*}{7} \\
\hline & & 3.3 & 100 & 0.5 & 14.7 & 30.4 & 26.4 & 8.0 & $\%$ & & \\
\hline \multirow{2}{*}{13} & \multirow{2}{*}{68.08} & 3404 & 1000 & 18 & 172 & 338 & 332 & 140 & S & ن & $y$ \\
\hline & & 3.4 & 100 & 1.4 & 13.8 & 27.0 & 26.6 & 11.2 & $\%$ & 0. & \\
\hline 10 & & 3346 & 1000 & 16 & 182 & 314 & 416 & 72 & S & ن & $\Lambda$ \\
\hline 18 & 06.92 & 3.3 & 100 & 1.3 & 14.6 & 25.1 & 33.3 & 5.8 & $\%$ & 0 . & $n$ \\
\hline 11 & 61 & 3302 & 1000 & 30 & 234 & 278 & 320 & 138 & s & ن & 9 \\
\hline 11 & 00.07 & 3.3 & 100 & 2.4 & 18.7 & 22.2 & 25.6 & 11.0 & $\%$ & 0. & 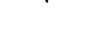 \\
\hline
\end{tabular}




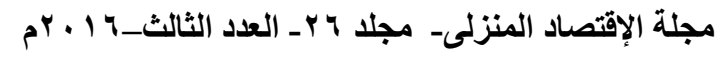

\begin{tabular}{|c|c|c|c|c|c|c|c|c|c|c|c|}
\hline \multirow{4}{*}{ الترتيب } & \multirow{2}{*}{ اللمتوسئ النوزية } & \multirow{2}{*}{ لموزون } & \multirow{2}{*}{ المجموع } & \multicolumn{5}{|c|}{ مستويات القياس } & \multirow{2}{*}{\multicolumn{2}{|c|}{ العينة }} & \multirow[b]{2}{*}{ التصميم } \\
\hline & & & & ضعيف & مقبول & جيد & جيل جداً & ممتاز & & & \\
\hline & \multirow{2}{*}{64.6} & 3230 & 1000 & 24 & 258 & 268 & 364 & 86 & ك & \multirow{2}{*}{$\begin{array}{l}=\dot{ }=0 \\
.\end{array}$} & \multirow[t]{2}{*}{1.} \\
\hline & & 3.2 & 100 & 1.9 & 20.6 & 21.4 & 29.1 & 6.9 & $\%$ & & \\
\hline \multirow{2}{*}{1} & \multirow{2}{*}{92.56} & 4628 & 1000 & 0 & 12 & 58 & 220 & 710 & ك & \multirow{2}{*}{$\begin{array}{l}=\dot{0} \\
\text { ○. }\end{array}$} & \multirow{2}{*}{11} \\
\hline & & 4.6 & 100 & 0.0 & 1.0 & 4.6 & 17.6 & 56.8 & $\%$ & & \\
\hline \multirow{2}{*}{11} & \multirow{2}{*}{64.92} & 3246 & 1000 & 12 & 236 & 332 & 334 & 86 & ك & \multirow{2}{*}{$\begin{array}{l}=\dot{0} \\
\text { ○. }\end{array}$} & \multirow{2}{*}{ ir } \\
\hline & & 3.2 & 100 & 1.0 & 18.9 & 26.6 & 26.7 & 6.9 & $\%$ & & \\
\hline \multirow{2}{*}{10} & \multirow{2}{*}{69.64} & 3482 & 1000 & 8 & 196 & 248 & 402 & 146 & ك & \multirow{2}{*}{$\begin{array}{l}=\dot{0} \\
\text { ○. }\end{array}$} & \multirow{2}{*}{ ir } \\
\hline & & 3.5 & 100 & 0.6 & 15.7 & 19.8 & 32.2 & 11.7 & $\%$ & & \\
\hline \multirow{2}{*}{ r } & \multirow{2}{*}{90.8} & 4540 & 1000 & 0 & 4 & 28 & 392 & 576 & ك & \multirow{2}{*}{$\begin{array}{l}=\dot{ }= \\
\text { ○. }\end{array}$} & $1 \leqslant$ \\
\hline & & 4.5 & 100 & 0.0 & 0.3 & 2.2 & 31.4 & 46.1 & $\%$ & & \\
\hline 10 & 69.64 & 3482 & 1000 & 46 & 170 & 276 & 272 & 236 & ك & ن & \\
\hline 10 & & 3.5 & 100 & 3.7 & 13.6 & 22.1 & 21.8 & 18.9 & $\%$ & 0. & 1. \\
\hline $1 \leqslant$ & 6792 & 3396 & 1000 & 12 & 190 & 324 & 338 & 136 & ك & ن & 17 \\
\hline & 01.92 & 3.4 & 100 & 1.0 & 15.2 & 25.9 & 27.0 & 10.9 & $\%$ & 0. & 11 \\
\hline 1 & 7777 & 3886 & 1000 & 0 & 180 & 178 & 218 & 424 & ك & ن & 18 \\
\hline & 11.12 & 3.9 & 100 & 0.0 & 14.4 & 14.2 & 17.4 & 33.9 & $\%$ & 0. & \\
\hline 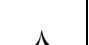 & 725 & 3628 & 1000 & 0 & 190 & 270 & 262 & 278 & s & ن & 1 \\
\hline & & 3.6 & 100 & 0.0 & 15.2 & 21.6 & 21.0 & 22.2 & $\%$ & 0 . & \\
\hline$y$ & & 3802 & 1000 & 25 & 106 & 177 & 426 & 266 & ك & ن & 14 \\
\hline & 10.04 & 3.8 & 100 & 2.0 & 8.5 & 14.2 & 34.1 & 21.3 & $\%$ & 0. & \\
\hline$\varepsilon$ & 85.76 & 4288 & 1000 & 0 & 6 & 178 & 338 & 478 & 5 & ن & T. \\
\hline & & 4.3 & 100 & 0.0 & 0.5 & 14.2 & 27.0 & 38.2 & $\%$ & 0. & 19 \\
\hline & 1737 & 73788 & 20000 & 279.0 & 3028.0 & 4677.0 & 6658.0 & 5358.0 & ك & ن & \\
\hline & 15.100 & 3.7 & 100 & 1.1 & 12.1 & 18.7 & 26.6 & 21.4 & $\%$ & 0. & " \\
\hline
\end{tabular}

ومن خلال الجدول (1) والخاص بالوزن النسبى لكل تصميم من التصميمات وفقا لأراء السادة

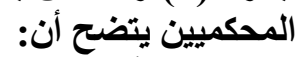

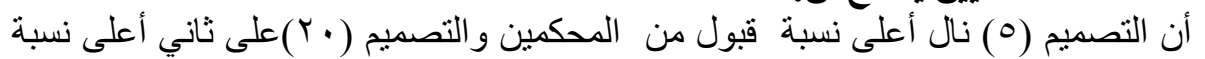

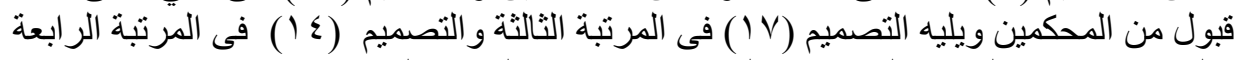
و التصميم( (1) فى المرنبة الخامسة و التصميم (1' (1) فى المرتبة السادسة. 


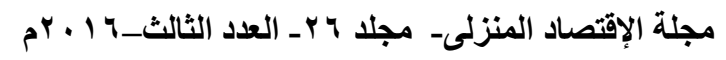

ومن خلال الجدول (2) والخاص بالوزن النسبى لكل تصميم من التصميمات وفقا لأراء عينه

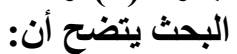

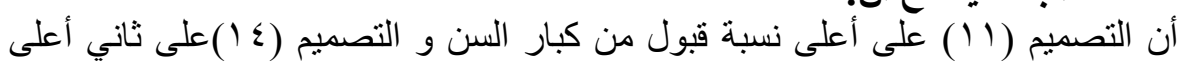

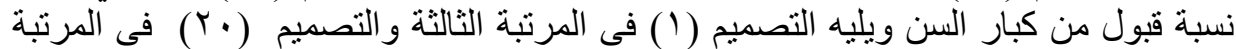

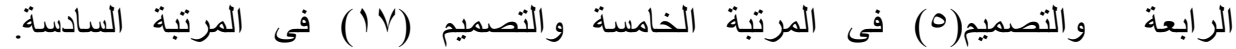

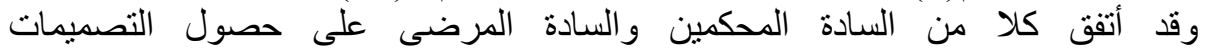

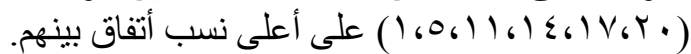

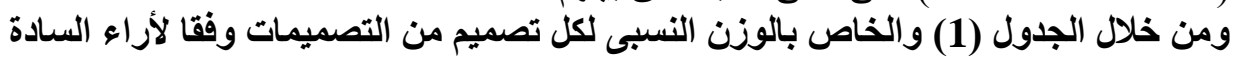

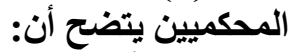

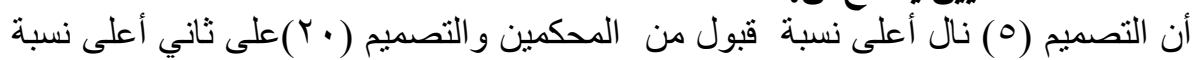

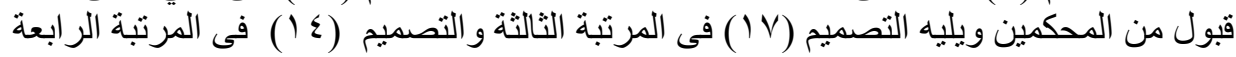

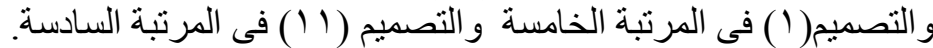
ومن خلال الجدول (2) و الخاص بالوزن النّار النسبى لكل تصميم من التصميمات وفقا لأراء الفئات

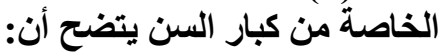

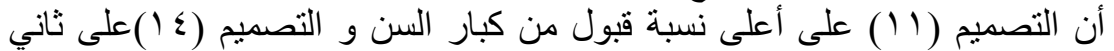

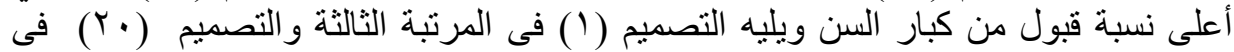

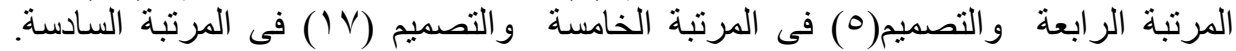

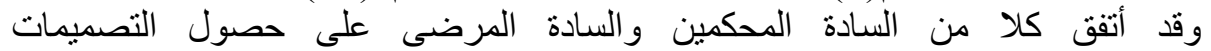

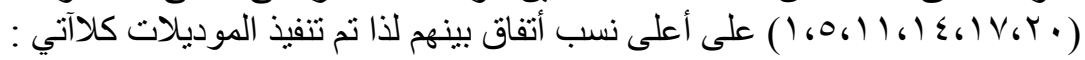

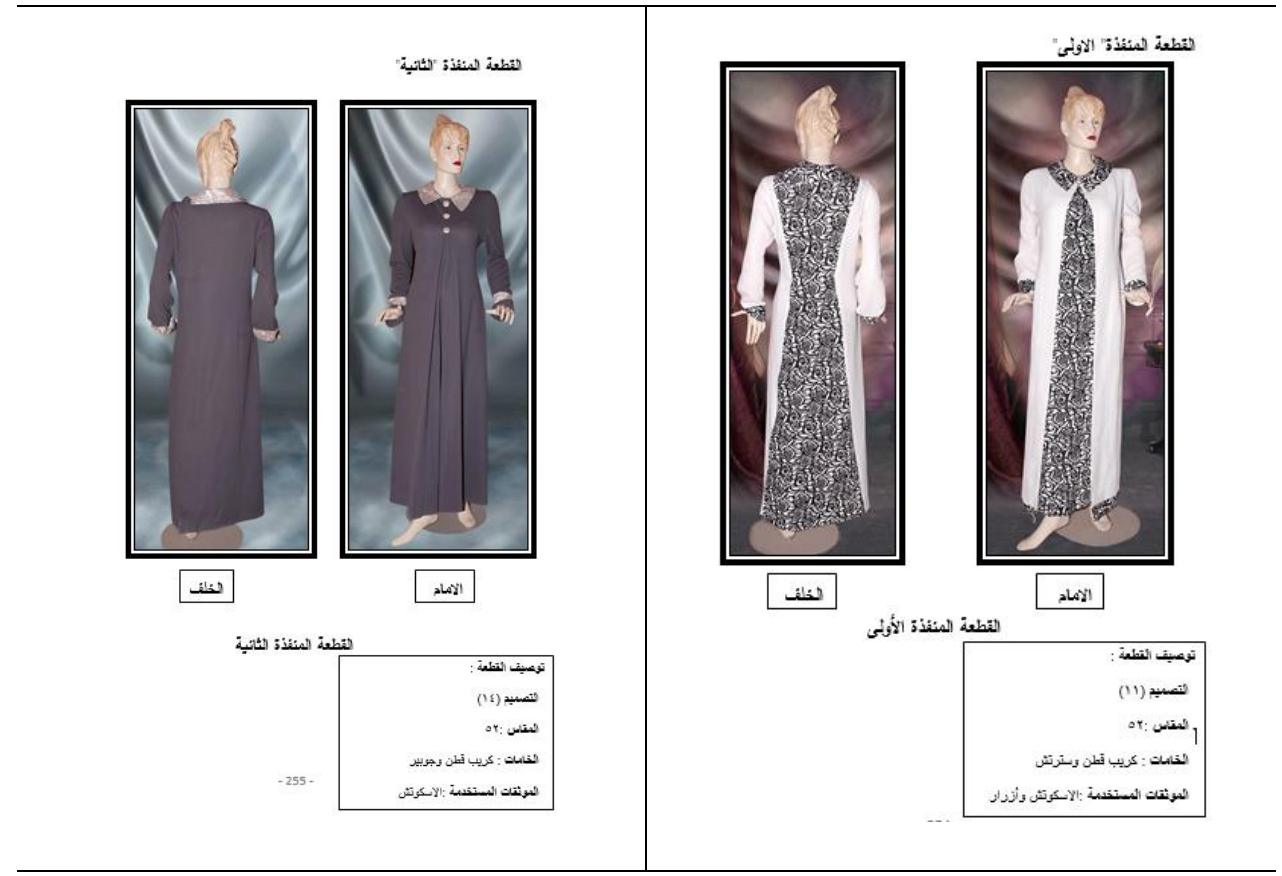




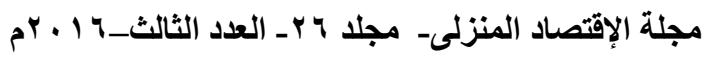

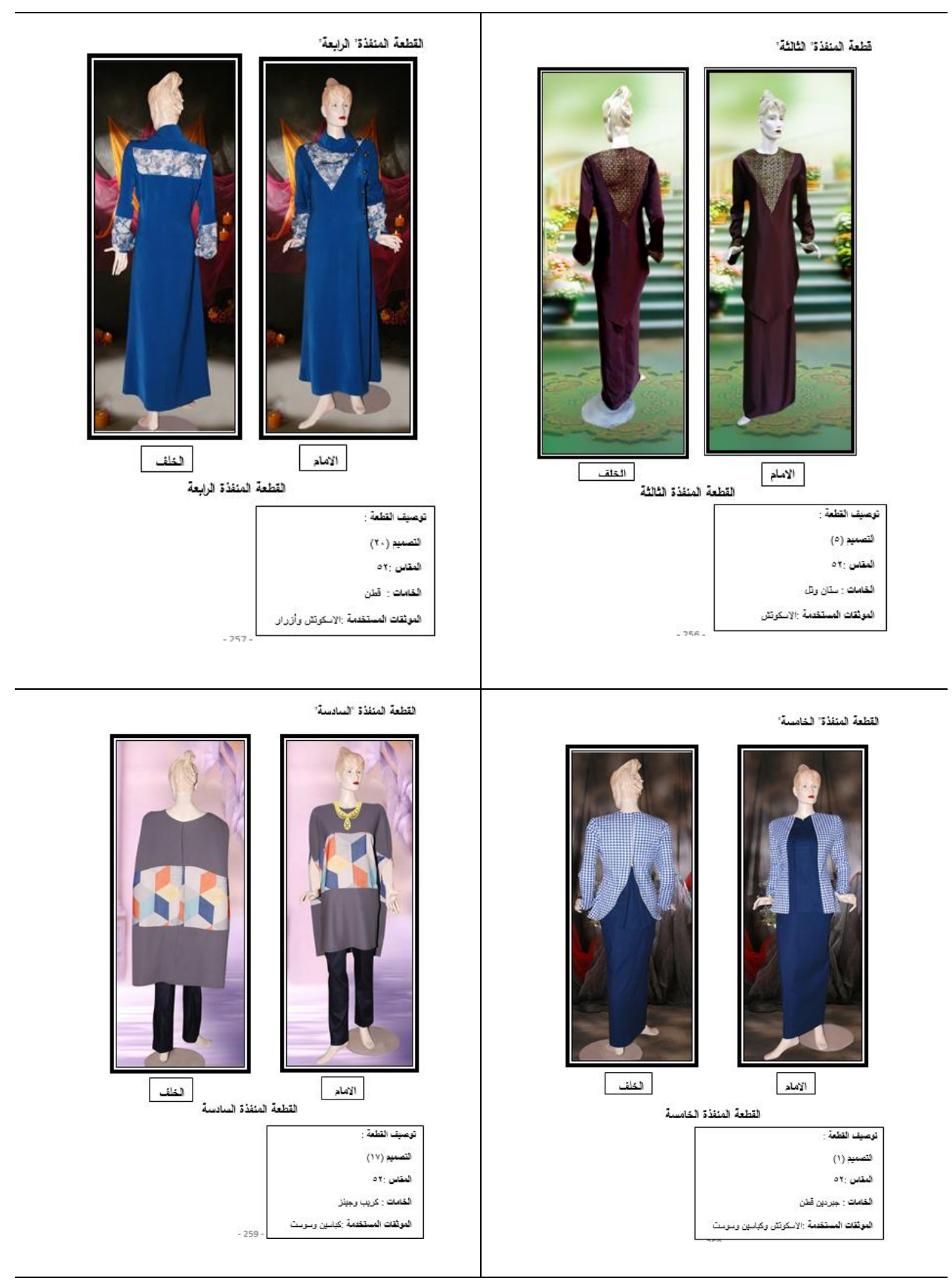




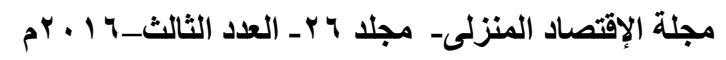

نتائج الاراسة وتفسيرها :

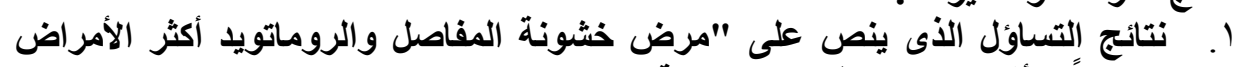

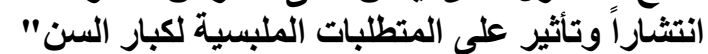

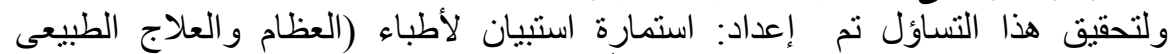

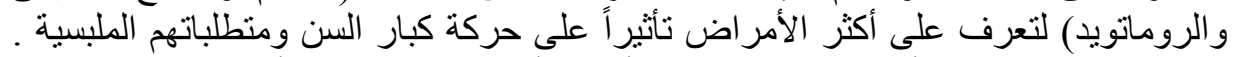

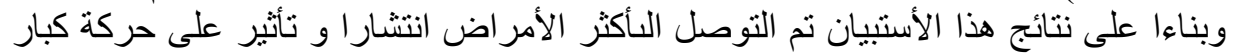
جدول يوضح الأمراض الأكثر انتثارا و تأثير على حركة كبار السن وفقا لأراء الأطباء

\begin{tabular}{|c|c|c|}
\hline النسبة المئوية & عدد الأطباء & وع المرض \\
\hline $100 \%$ & 18 & 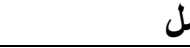 \\
\hline $50 \%$ & 11 & (الجلطة) \\
\hline $61.1 \%$ & 9 & \\
\hline $5.6 \%$ & 1 & ك الطرفية \\
\hline \multirow[t]{2}{*}{$11.1 \%$} & 2 & ن القطنية \\
\hline & & المفاصل \\
\hline
\end{tabular}

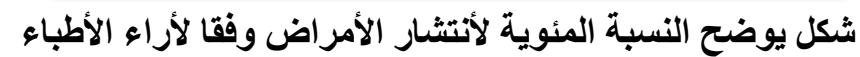

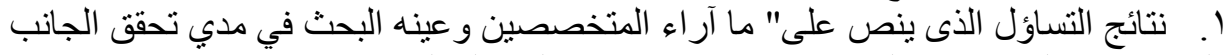

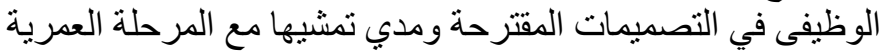

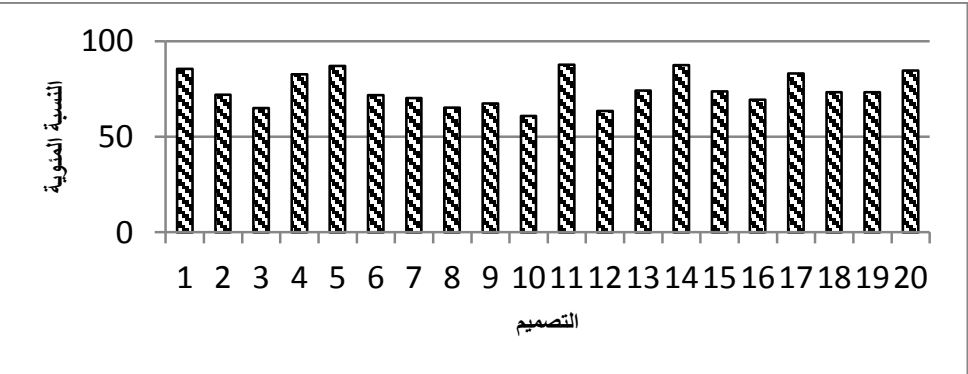

نتائج التساؤل الذى ينص على ما آراءالمتخصصين وعينة البحث في أن التصميمات المقترحة تؤثر إيجابياً على الحالة النفسية 


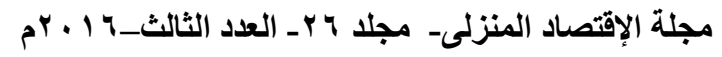
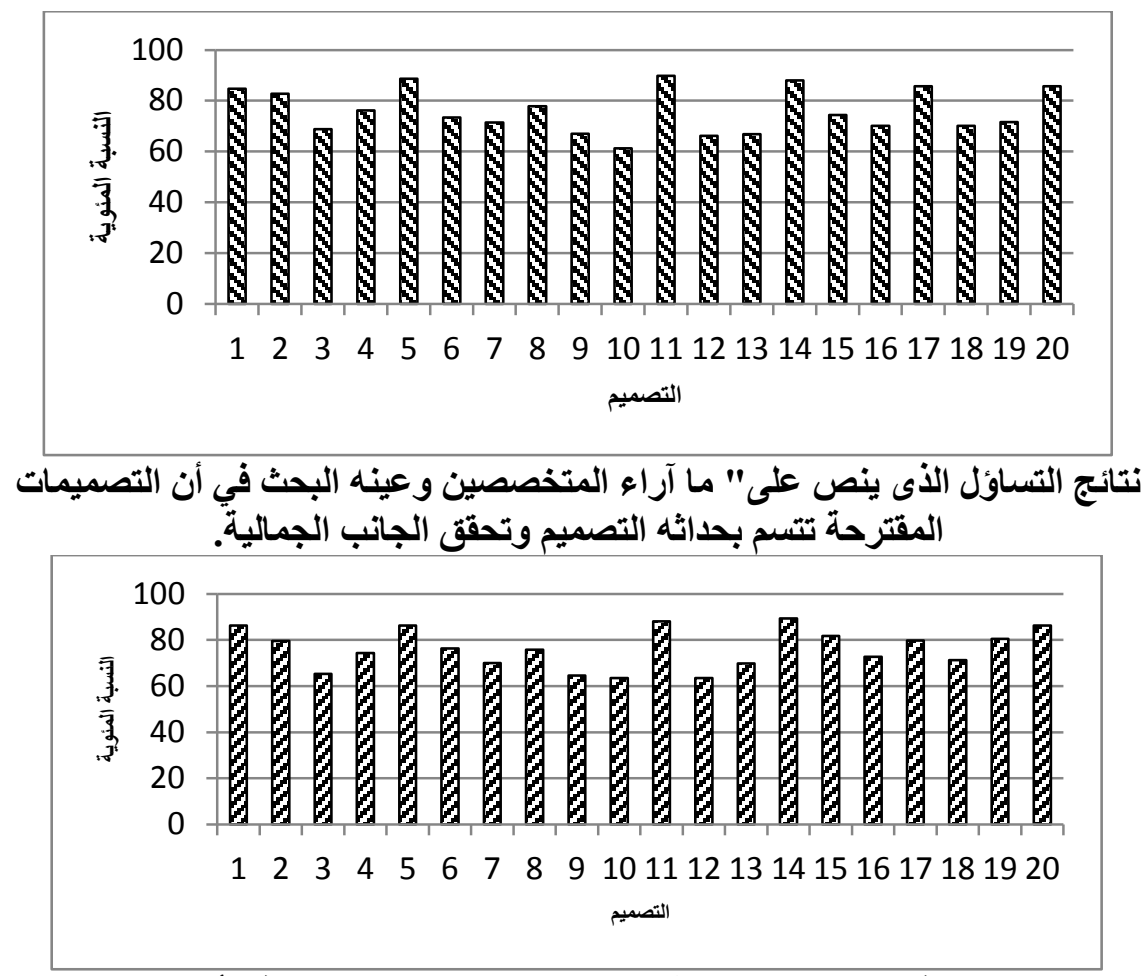

نتائج التساؤل الذى ينص على" ما آراء المتخصصين وكبار السن في أن التصميمات المقترحة توفر الراحة للقائمين على رعاية تلك الفئة.

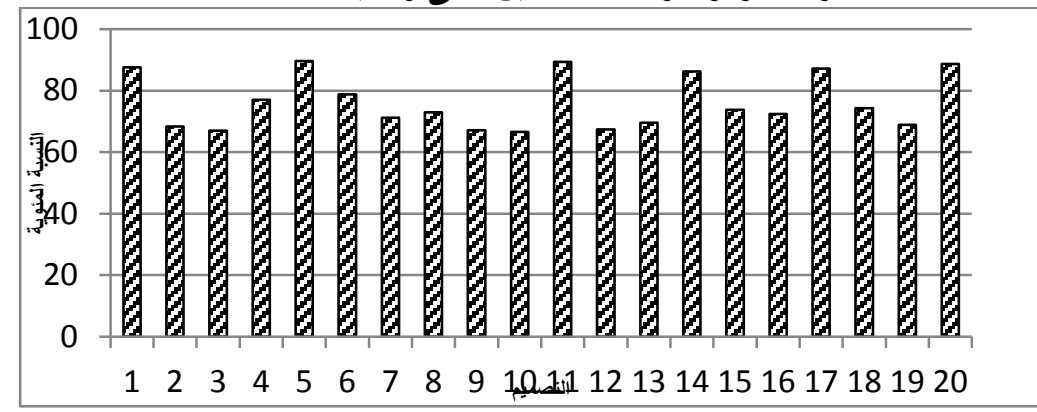

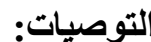

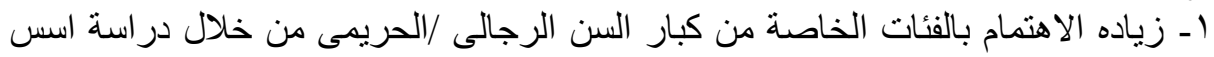

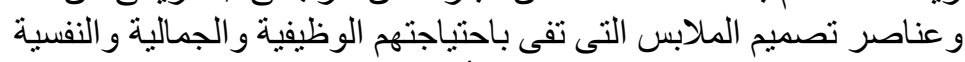

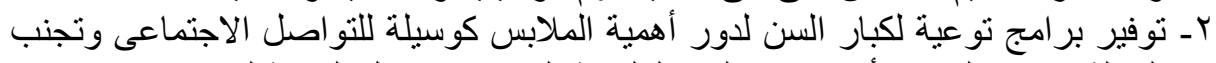

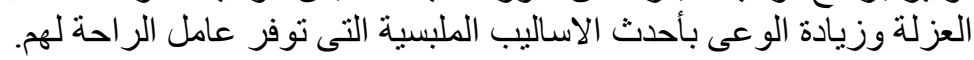


مجلة الإقتصاد المنزلى- مجلد 7 ـ العدد الثالث_r 1 • r م

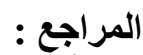

ا - أحمدعبد السلام أبو الحسن :"برنامج تدريبى مقترح مساعد لتأهيل الركبة المصابة بالخشونة " رسالة دكتور اه ،قسم علوم الصحة الرياضية ، كلية التربية التربية الرياضية

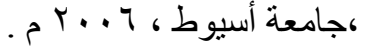

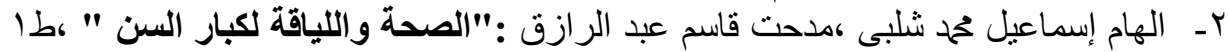

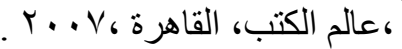

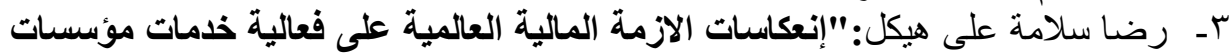

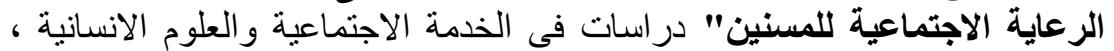

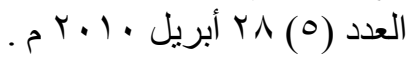

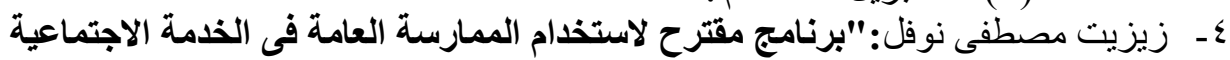

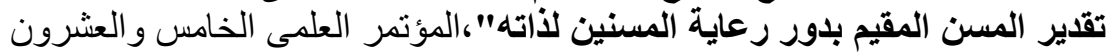

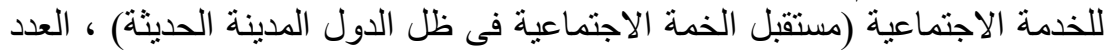

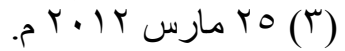

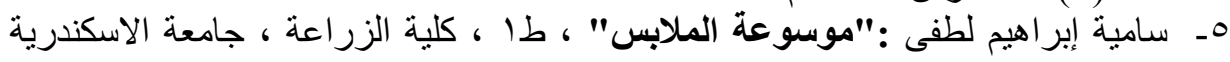

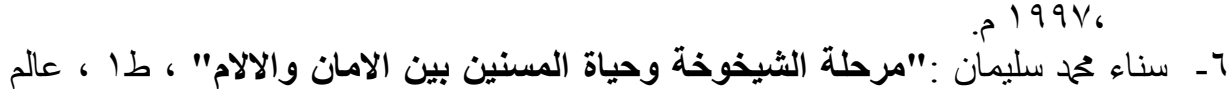

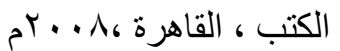

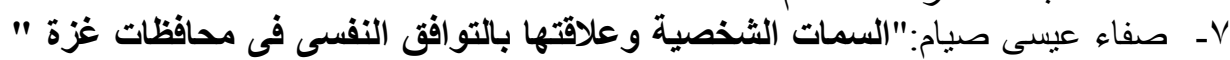

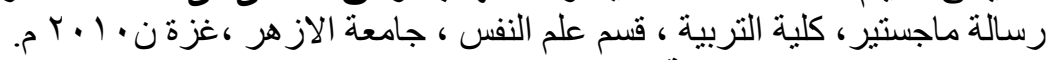

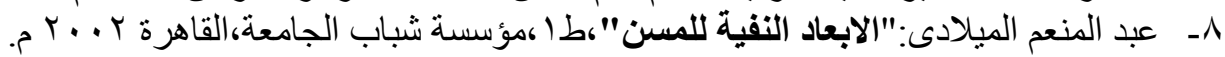

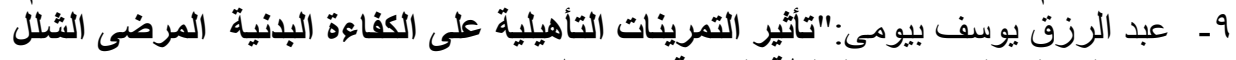

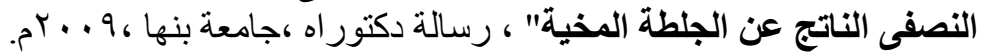

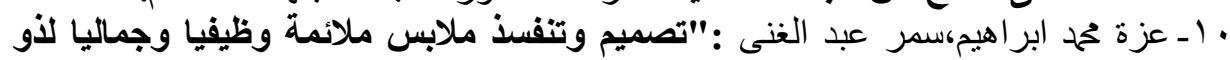

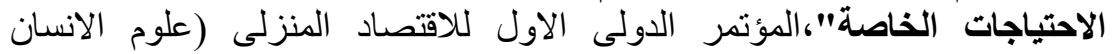

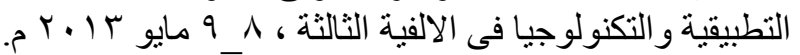

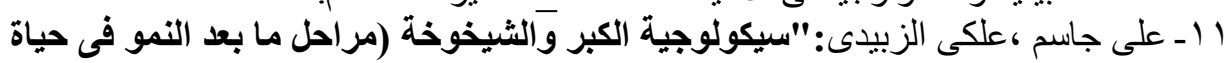

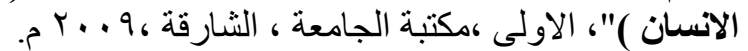

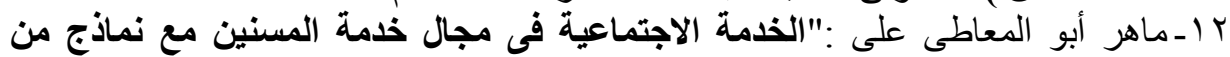

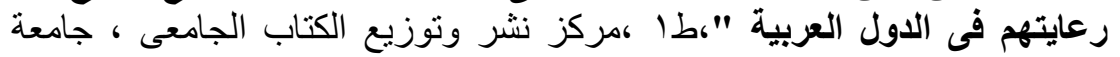

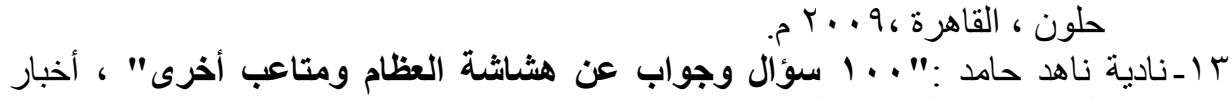

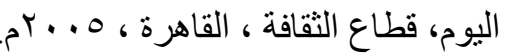

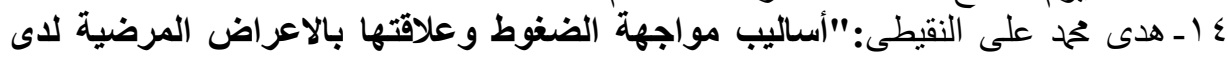

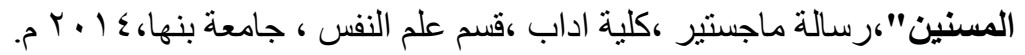




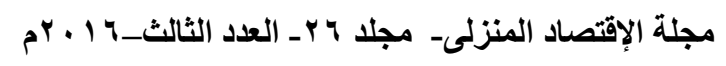

\title{
Functional and aesthetic perspective for (osteoarthritis - rheumatoid arthritis) patients clothes for elderly ladies
}

\begin{abstract}
:
Human pass three stages the first phase of weakness (childhood) and then phase power (the youth) and then the second stage of vulnerability namely aging and old age, and that accompany changes in multiple aspects of physical, psychological, social, physical Changes including:

Lack of muscular control, lack of ability to catch things, the loss of efficiency and effectiveness of the bones of the body, exposed to brittle fractures, changes in the skeleton and the skin and wrinkles, as well as mental disorders and difficulty in compatibility with others, and diseases that abound infection in this age group (stroke - osteoarthritis rheumatoid arthritis).

The research problem lies in the possibility of achieving functional and aesthetic aspects of elderly ladies clothes to fit the needs of the search category, both psychological aspects or comfort when use

The goal of research is to provide clothing designs meet the needs of the search category, functional and aesthetic research and reach to provide 20 model fit to the search category with surrounding processors used type based on the use of arbitration form of the masters of experts and specialists, as well as a form for the search category. It calculated the proportion of the agreement and through the implementation of 6 pieces and judged by the jury specialists in the field of clothing and textiles to ensure the achievement of the functional and aesthetic aspects of the proposed clothes for elderly ladies .
\end{abstract}




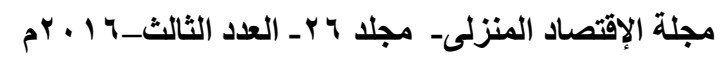

ملحق رقم ( ) لقياس مدى ملاعمة التصميمات المقترحة للنواحى الوظيفية والجمالية

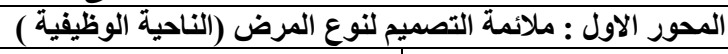
التصميم التطية

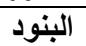

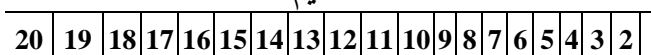

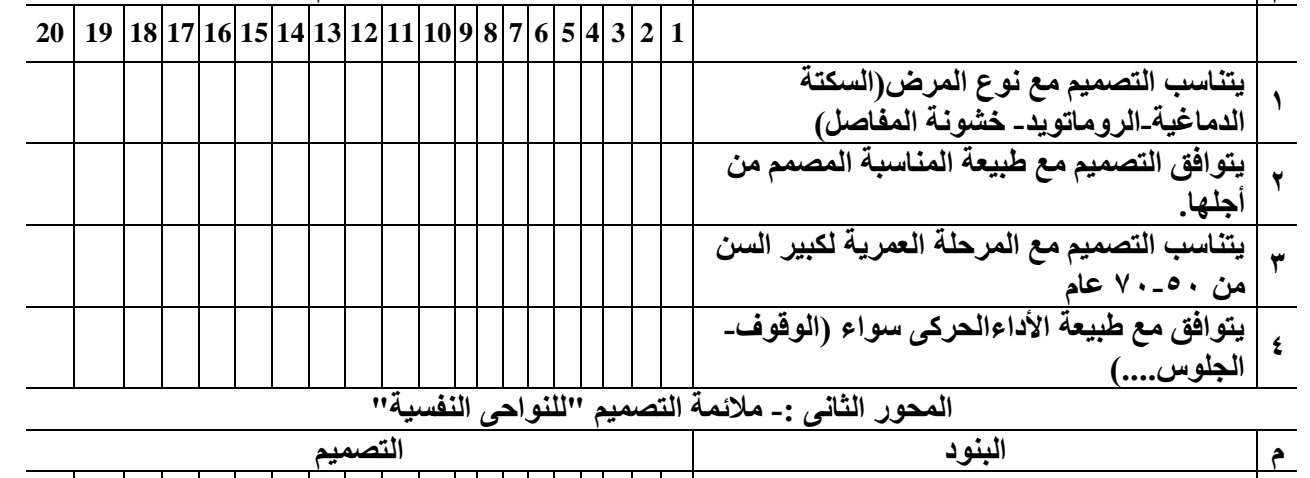

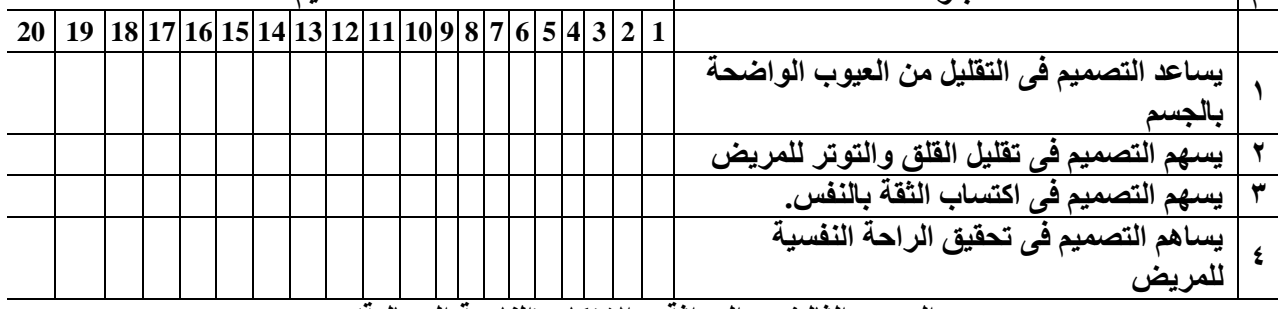
المحور الثالث :- الحداثة و الابتكار (الناحية الجمالية)

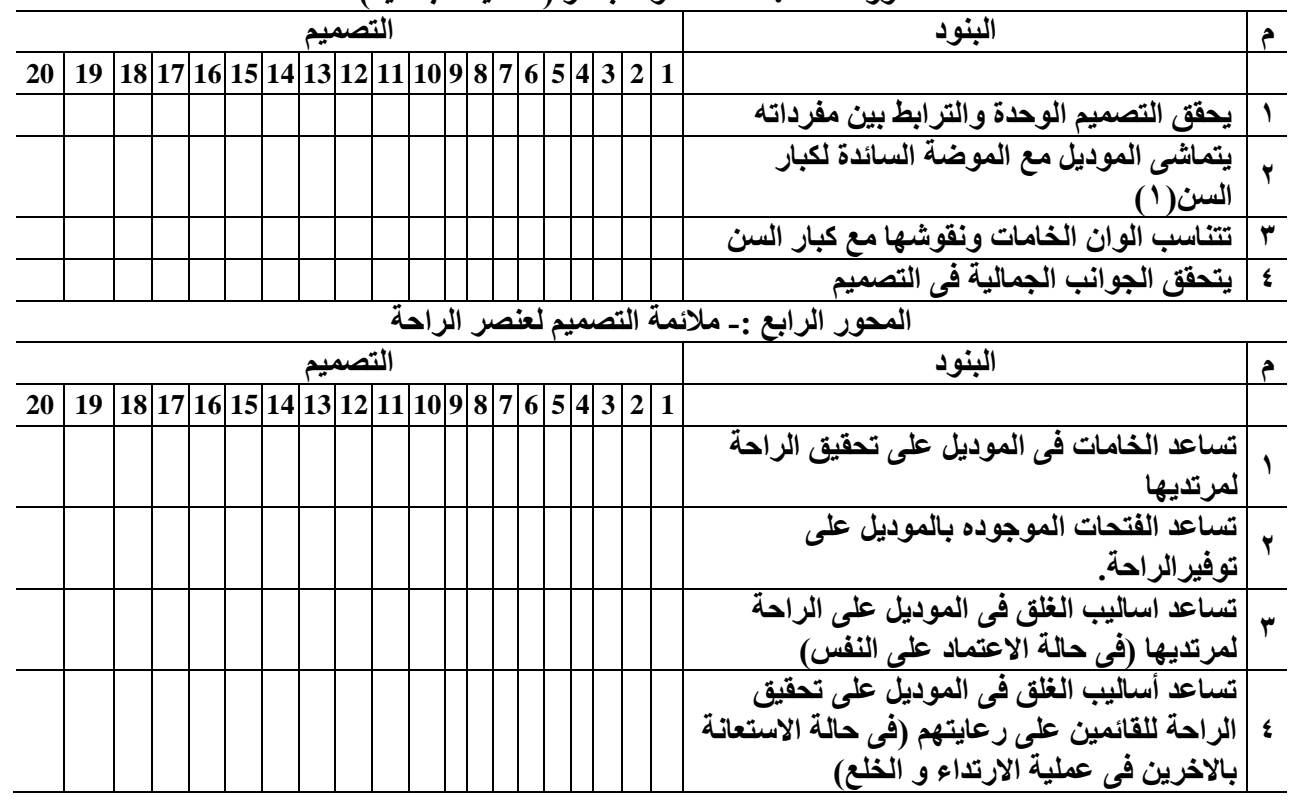




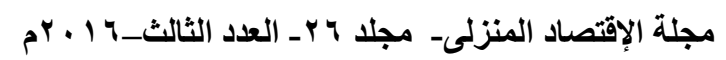

ملحق رقم (r) لقياس مدى ملاعمة القطع المنفذة لفئة البحث

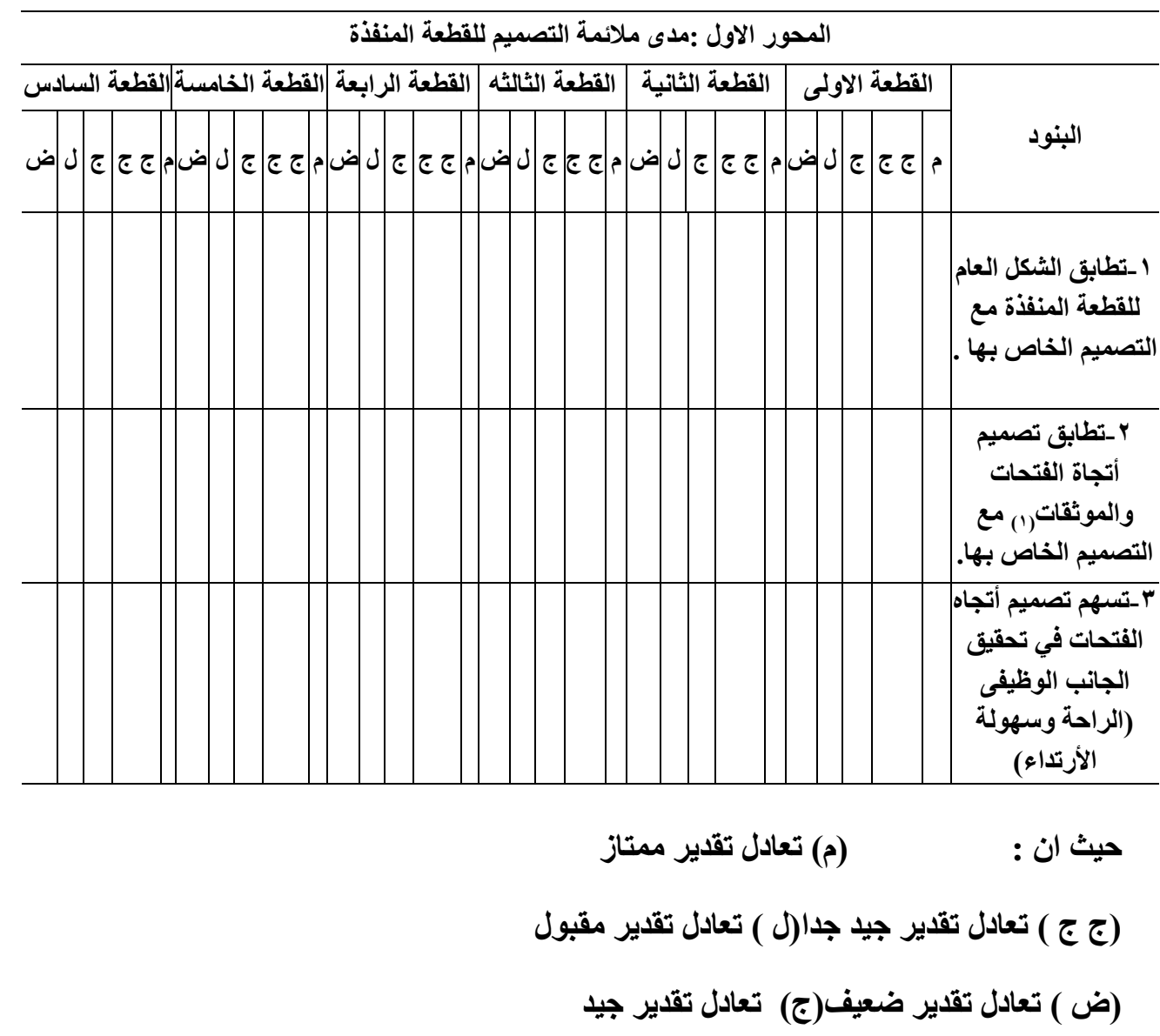

M 